NBER WORKING PAPER SERIES

\title{
ARE EXCHANGE RATES \\ EXCESSIVELY VARIABLE?
}

\author{
Jeffrey A. Frankel \\ Richard Meese
}

Working Paper No. 2249

\author{
NATIONAL BUREAU OF ECONOMIC RESEARCH \\ 1050 Massachusetts Avenue \\ Cambridge, MA 02138 \\ May 1987
}

Support from the Sloan Foundation is gratefully acknowledged. The research
reported here is part of the NBER's research program in reported here is part of the NBER's research program in International Studies. Any opinions expressed are those of the authors and not those
of the National Bureau of Economic Research. 


\section{Are Exchange Rates Excessively Variable?}

\section{ABSTRACT}

"Unnecessary variation" is defined as variation not attributable to variation in fundamentals. In the absence of a good model of macroeconomic be answered by comparing the varianchange rates excessively variable?, "cannot variance of a set of fundamentals. The of the actual exchange rate to the equations to explain exchange rat. This paper notes the failure of regression macroeconomic variables. It notes as wellts even using contemporaneous unbiasedness of the forward exchange well the statistical rejections of the then argues that, given these results, there a predictor of the spot rate. It variance-bounds tests and bubbles tests.

The paper also discusses recent results on variation in the exchange risk premiums arising from variation in conditional variances, both as a source of It finishes with a ford rate tests and as a source of variation in the spot rate. stabilizing or destabilizing of whether speculators' expectations are that it is possible that exchange measured by survey data. The paper concludes for example, when there are specue rates have been excessively variable - - as, try systematically to exploit their ive bubbles -- but that if policy-makers rates, they may see their current credibility vanish.

Jeffrey A. Frankel

Department of Economics

University of California

Berkeley, CA 94720

(415) $642-8084$
Richard Meese

School of Business Administration University of California

Berkeley, CA 94720

(415) 642-1435 


\section{Are Bxchange Rates Bxcessively Variable?}

Jeffrey A. Frankel

Richard Meese

Apri1 1987

This paper was written for the NBER Macroeconomics Annual Conference, Cambridge, Ma., March 13-14, 1987 . An abridged version will appear in like to thank Joe Mattey for Business and assistance, Andrew Rose for comments review of the manuscript.

\section{OU TLINE}

I. The Meaning of "Excessive Variability"

1. Introduction

2. Factors Determining "Excessive Variability"

(a) disturbances unrelated to fundamentals?

(b) degree of substitutability?

(c) are expectations stabilizing or destabilizing?

II . Random Walk Results

1. Nonstationarity of Nominal and Real Exchange Rates

(a) nominal

(b) real

2. Regressions of Exchange Rate Determination

3. Interpreting Tests of Bias in the Forward Discount

(a) the stationarity argument for changes rather than levels

(b) real returns rather than nominal returns

(c) peso problem

(d) risk premium

4. Variance-Bounds and Bubbles Tests

(a) bubbles tests

(b) variance-bounds tests

III. The Exchange Risk Premium

1. Implications of Portfolio-optimization with Constant Variance

2. Implications of Time-Varying Covariances

IV. Survey Data and Heterogenous Expectations

1. Measuring Stabilizing and Destabilizing Expectations

2. Conclusion 


\section{The Keaning of "Bxcessive Variability"}

The proponents of floating exchange rates before $1973 \mathrm{did}$ not promise that exchange rates would necessarily be stable under such a system, but only that they would be as stable as the underlying macroeconomic fundamentals. ${ }^{1}$ Nevertheless, the widespread feeling is that exchange rates have turned out to be more volatile than necessary. Many practitioners believe that exchange rates are driven by psychological factors and other irrelevant market dynamics, rather than by ecomomic fundamentals. Support seems to have grown 1n the 1980s for "targetzone" proposals, or some other sort of government action to stabilize exchange rates. 2

Economists have understood for some time that under conditions of high international capital mobility, currency values will move sharply and unexpectedly in response to new information. Even so, actual movements of exchange rates have been puzzling in two major respects. First, the proportion of exchange rate changes that we are able to predict seems to be not just low, but zero. According to rational expectations theory we should be able to use our models to predict that proportion of exchange rate changes that is correctly predicted by exchange market participants. Yet neither models based on economic fundamentals, nor simple time series models, nor the forecasts of market participants as reflected in the forward discount or in survey data, seem able to predict better than the lagged spot rate. Second, the proportion of exchange rate movements that can be explained even after the fact, using contemporaneous macroeconomic variables, is disturbingly low. 


\section{Introduction}

When we return to the basics, to ask what is actually known about the cructal building blocks of exchange markets, we find one question that has been answered and three that have not. The one conclusion about which there is no longer serious disagreement is that monetary disturbances have real effects. The 1980s have witnessed very large swings in real money supplies, real interest rates, and--more demonstrably--real exchange rates, convincing most observers that there is not an exogenous instantly-equilibrating optimally-functioning real economy that can be divorced from monetary factors. ${ }^{3}$ It follows that even if financial markets do operate efficiently--a proposition that we neither automatically presuppose nor rule out in this paper--one cannot make an argument against government intervention in foreign exchange markets on the grounds of Arrow-Debreu optimality alone.

There are three questions that have yet to be satisfactorily answered, and that are examined in this study. Question 1: How responsive are investors' demands for domestic and foreign assets to expected rates of return, that is, what is the degree of substitutability? Question 2: How do investors form expectations? In particular, how much weight do they give to the contemporaneous spot rate and how much to other factors? Question 3: How does the actual process governing the spot exchange rate correspond to the process embodied in investors' expectations, that is, are expectations rational? As we will see, these questions together contain the essential elements necessary to evaluate claims of excessive exchange rate variability. 
We will be trying to shed light on these questions by drawing on several areas of the existing empirical literature on the spot and forward exchange markets, as well as on some new empirical results. Empirical topics to be covered, if only briefly, are non-stationarity of the nominal and real exchange rates, regression tests of exchange rate determination, forward market efficiency, variance-bounds tests and bubbles tests, portfolio-optimization and the exchange risk premium, and expectations survey data.

However, we begin by considering the more general motivation for answering the three questions stated above: how knowing the answers to them might help answer whether exchange rate fluctuations have been unnecessarily large.

\section{Factors in Deteratning "Bxcessive Variability"}

In seeking to get a handle on the question of alleged excessive variability, we specify as general a model of the spot exchange rate as possible.

$$
s=s\left(l, i-i *, \Delta s^{e}, u\right)
$$

We represent fundamental determinants such as asset supplies by $\ell$, the interest differential by $i-i^{*}$, investors' expected future change in the exchange rate by $\Delta s^{e}$, and any short-term random factors by $u$. The last will be found necessary if we are to confront regression results, which under the best of circumstances have relatively low $R^{2}$. It will also be found necessary if we are to consider the issue of alleged short-term volatility unrelated to fundamentals. 
The equation is so general that it could be interpreted as the old balance-of-payments flow approach to exchange rate determination, where $\ell$ represents factors affecting the current account and the other three variables are determinants of the capital account. We shall follow the stock approach here however, in which the focus is on stocks of assets rather than flows.

We can impose additional structure on equation (1) by defining $\ell$ to be specifically the log of the supply of domestic assets minus the $\log$ of the supply of foreign assets, defining $s$ to be the $\log$ of the spot price of foreign exchange, imposing homogeneity, and assuming also that the two components of expected returns enter with coefficients of equal magnitude:

$$
s=\ell-L(1-1 *-\Delta s e ; u)
$$

In equation (2), $\ell$ is the relative supply of domestic assets and $L$ is the relative demand for domestic assets, which depends positively on $r p \equiv i-i^{*}-\Delta s{ }^{e}$, the risk premium or expected excess rate of return on domestic assets. In a portfolio-balance approach, for example, we could assume that the share of the portfolio allocated to foreign assets, $x$, is linearly related to the risk premium on foreign assets: 4

$$
\mathbf{x}=\mathrm{A}-\mathrm{B}(\mathrm{rp})
$$

Then (2) would hold, with

$$
-L(\cdot) \equiv \log (x(\cdot))-\log (1-x(\cdot)), \text { and }
$$

$$
d L / d(r p)=\left(\frac{1}{x}+\frac{1}{1-x}\right) B
$$


We can now use equation (2) to consider the question of exchange rate variability. It seems likely that regardless whether the fundamentals term $\ell$ is defined to include only money supplies or also supplies of bonds and other assets, one cannot in fact explain observed variability in $s$ by variability in $~ l$. This is the implication of both volatility tests and regressions of the spot rate against fundamentals such as asset supplies. 5 The same conclusion seems to hold as well if the fundamentals term $\ell$ is defined to include the current account.6

We are thus led to consider the other two terms in equation (2), which are determinants of asset demands rather than asset supplies: $1-1 *-\Delta s e$, and $u$. The expectations formation process is key to the question of variability, whether as a source of fluctuations or as "stabilizing speculation," moderating the effect of disturbances that originate in the other terms. To allow for both the bandwagon effects that are so often cited by participants in the exchange market, 7 and the stabilizing expectations that are the norm in models based on economic fundamentals, we can specify expected depreciation to be the sum of an extrapolative or "bandwagon" expectations term and a regressive expectations term:

$$
\Delta s_{t}^{e}=g\left(s_{t}-s_{t-1}\right)+\theta\left(\bar{s}_{t}-s_{t}\right)
$$

Consider a disturbance in $u$, or any of the other terms, that increases $s$. To the extent that $g>0$, "speculators," or investors, will expect future increases in $s$, will shift their asset demand into foreign assets, and will thereby exaggerate the increase in $s$. To 
the extent that $\theta>0$, they will expect a return back to the equilibrium value $\bar{s}_{t}$, and will thereby dampen the fluctuation. If $g>\theta$, expectations are said to be elastic or destabilizing; if $g<\theta$, they are said to be inelastic or stabilizing.

It is important to note that equation (5) could be fully consistent with rational expectations in a variety of models. For example, in the case $g=0$, regressive expectations can be rational in the sticky-price monetary ("overshooting") model of Dornbusch (1976), where the rational value of $\theta$ depends on the speed of adjustment of the price level, or in the portfolio-balance model of Kouri (1977) and Rodriguez (1980), where it depends on the speed of adjustment of the stock of foreign claims.$^{8}$ In the case $\theta=0$ on the other hand, extrapolative or "bandwagon" expectations could be rational in models of speculative bubbles such as Blanchard and Watson (1982) or Dornbusch (1982). Finally, in the case $g=\theta=0$, static expectations $(\Delta s=0)$ could be rational if the true exchange rate process is a random walk, a result consistent with recent empirical findings. 9

An alternative interpretation of equation (5) is a speculative bubble: speculators think that there is a probability $\theta$ that the bubble will burst within the coming period and the spot rate will return all the way to equilibrium $\bar{s}$, and a probability $(1-\theta)$ that it will continue on a bubble path (in which case it will increase at a rate equal to $g /(1-\theta)$ times the rate at which it has already been increasing).10 Again, such a bubble could be rational, if the actual spot rate turns out to follow the same process. 
Friedman (1953) argued persuasively that speculators who had a destabilizing effect would be "buying high and selling low," and thus would lose money and be driven out of the market. In modern terms, he argued that destabilizing speculation would be inconsistent with rational expectations. But the modern realization that one can have rational stochastic speculative bubbles, in which each speculator stands to lose money if he doesn't go along with the others, has all but destroyed the classic Friedman argument.

A linearized form of the equation of spot rate determination (2) is now

$$
s_{t}=\ell_{t}-\beta\left(i_{t}-i_{t}^{*}-g\left(s_{t}-s_{t-1}\right)-\theta\left(\vec{s}_{t}-s_{t}\right)\right)+u_{t}
$$

where $\beta$ is the degree of substitutability $d L / d(r p)$ (as, for example, in equation (4)).

Volatility will be high, in the sense that the variability of $s$ will be high with $\ell$ and $i-i^{*}$ given, if the variability of $u$ is high, if $\beta g$ is high, and if $\beta \theta$ is low. Indeed if we were interested in the one-period effect of $u_{t}$ alone, on the theory that this is the source of short-term uncertainty, then the conditional variance of $s_{t}$ would be given by

$$
\left(\frac{1}{1+\beta(\theta-g)}\right)^{2} \operatorname{var}\left(u_{t}\right) \text {. }
$$

Equation (7) illustrates in a simple way a conflict that exists in discussions of excessive exchange rate volatility. Some economists, such as Tobin (1978), argue that exchange rates are too variable because financial markets are "excessively efficient," that capital sloshes back 
and forth among countries in response to trivial disturbances, and that a tax on foreign exchange transactions would reduce volatility. This view says that volatility is high because $B$, the degree of substitutability, is high. But there is another view, associated with Mckinnon (1976), that exchange rates are too variable because of a "deficiency of stabilizing speculation," in other words, because $\beta$ is too low. The apparent paradox can be resolved by noting that the variance is positively related to $B$ (the Tobin case) if $\theta<g$, (and $1>B(g-\theta)$ ), because in that case the expectations to which investors react are destabilizing. The variance is negatively related to $\beta$ (the McKinnon case) if $\theta>g$, because in that case expectations are stabilizing. To analyze the possible sources of exchange rate volatility, we need to consider both the degree of substitutability and whether expectations are stabilizing.

In this paper we will be seeking enlightenment on the empirical magnitude of these parameters. In doing so we are leaving out much that is central to the macroeconomics of exchange rates. Even if the expression in (7) is small, one could still make many arguments for or against restricting the movements of the exchange rate that result from changes in macroeconomic factors such as $\ell$ or $i_{-1 *}$ (assuming it could be done) .

For example, many economists belleve that the strong real appreciation of the dollar in the early 1980 s can be attributed to a shift in the monetary-fiscal policy $m$ ix that raised the interest differential $1-I^{*}$ and made U.S. assets more attractive to world investors. Some believe further that it would not have been desirable to force down the 
value of the dollar, for example by forelgn exchange intervention or the imposition of controls to shut off the capital inflow (even assuming it possible), in the absence of reductions in the fiscal budget deficit. The argument is that U.S. interest rates would have risen even more than they in fact did, crowding out domestic investment. 11

To evaluate such arguments, one should probably specify an objective function, including such variables as output, inflation, trade balance and investment, and try to judge whether letting the market determine the exchange rate is likely to result in a higher value of the objective function than proposed plans to stabilize the exchange rate. Such questions are beyond the scope of this paper. 12

Our interest here is only in the question whether foreign exchange markets can fairly be said to be working well. If allegations are found justifled that speculative bubbles, a failure of market efficiency, or random fluctuations, are raising exchange rate variability needlessly, then it could be said that the markets are not working well. The possibility might in that case exist of obtaining lower exchange rate variability without cost. There is a wealth of empirical results that can be brought to bear. 


\section{Randon Walk Results}

A variety of different econometric approaches seem to end up at the same conclusion, that the exchange rate follows a random walk. In this part of the paper we discuss the apparent inability to forecast future changes in the exchange rate using either

(1) the past time series of the process itself (section II.1),

(ii) macroeconomic fundamentals (section II.2), or

(iii) the forward exchange market (section II.3).

We then discuss what else, if anything, can be learned from the currently popular variance-bounds and bubbles tests.

\section{Nonstationarity of Woninal and Peal Bxchange Rates}

It is now widely recognized that the linear time series representation of the natural logarithm of either spot or forward exchange rates is best described by a random walk process. ${ }^{13}$ Formal statistical tests for the presence of a unit root in the autoregressive representation of the logarithms of spot and forward exchange rates were first conducted by Meese and Singleton (1982). These unit root tests, pioneered by Fuller (1976) and his students, are known to have low power against borderline stationary alternatives. However, we find the superior out-of-sample forecasting performance of the random walk model, over time series models where the unit root is not imposed, to be powerful evidence in favor of the unit root null. Finally, more recent statistical tests of the unit root hypothesis that are robust to conditionally heteroskedastic disturbances (Phillips (1985)) also 
support the unit root hypothesis. This is an important methodological advance, since $i t$ is also widely recognized that exchange rate variability tends to be episodic; see Cumby and obstfeld (1984) for tests of conditional heteroskedasticity in nominal exchange rates. 14

Nonstationarity in the nominal exchange rate does not create problems for standard theories of exchange rate determination. In the monetary models, if the money supply is nonstationary in levels, or even in changes, then the exchange rate will be nonstationary in levels or changes. We have only to be careful how we specify our econometric tests of nominal exchange rates, preferring first differences over levels in general. Nonstationarity in the real exchange rate is considered by some to be a more serious matter however. If the real exchange rate follows a random walk, then there is no tendency to return to purchasing power parity, and seemingly no limit on how far out of line one country's prices can get from another's.15

Not long ago, purchasing power parity was widely accepted. It was argued on a priori grounds that the law of one price should be enforced at least for traded goods once transport costs were accounted for: If automobiles were selling at a lower price in Germany than in the United States, international arbitrageurs should buy them in Germany and sell them in the United States, raising the price in one country or lowering it in the other until equality was restored.

The empirical evidence against PPP in level form is overwhelming. The enormous real appreciation of the dollar in the early 1980s convinced the remaining doubters, but abundant statistical evidence was there all along. For example, Krugman (1978, p. 406) computed for the 
floating rate period July 1973 - December 1976 standard deviations of the (logarithmic) real exchange rate equal to 6.0 percent for the pound/dollar rate and 8.4 percent for the mark/dollar rate. He also computed serial correlation coefficients for PPP deviations of .897 and .854, respectively, on a monthly basis, equal to .271 and .150 on an annual basis. The serial correlation, coefficient is of interest because it is equal to one minus the speed of adjustment to PPP.

Table 1 shows updated annual statistics on the real exchange rate between the United States and Great Britain. During the floating rate period 1973-84, there is a significant time trend, and a standard deviation of 15.4 percent. The serial correlation in the deviations from PPP is estimated at .720, with a standard error of .248 . (The equation estimated is $\left(\mathrm{er}_{t+1}-\overline{\mathrm{er}}_{t+1}\right)=\operatorname{AR}\left(\mathrm{er}_{t}-\overline{\mathrm{er}}_{t}\right)+\varepsilon_{t+1}$, where er is the real exchange rate and $\overline{\mathrm{er}}$ is the long-run equilibrium level, alternatively estimated as the sample mean or a time trend, and $A R$ is the autoregressive coefficient.) This means that the estimated speed of adjustment to PPP is .280 per year and that one can easily reject the hypothesis of instantaneous adjustment.

From the ashes of PPP, a phoenix has risen. In response to findings such as those reported here, some authors have swung from one extreme, the proposition that the tendency of the real exchange rate to return to a constant is complete and instantaneous, to the opposite extreme that there is no such tendency at all. But there is even less of an a priori case why PPP should hold in rate-of-change form than in the level form. 
Table 1

Purchasing Power Parity between the United States and the United Kingdom 1869-1984

\begin{tabular}{lcccc} 
& $1973-1984$ & $1945-1974$ & $1945-1984$ & $1869-1984$ \\
\hline $\begin{array}{l}\text { Mean absolute deviation } \\
\text { Standard deviation }\end{array}$ & .121 & .075 & .106 & .093 \\
Time trend & .154 & .092 & .146 & .122 \\
& $-.001 *$ & $.006 *$ & -.0004 & .009 \\
$\begin{array}{l}\text { Autoregression } \\
\text { of deviations from mean }\end{array}$ & $(.0003)$ & $(.002)$ & $(.0022)$ & $(.013)$ \\
& $(.248)$ & $(.132)$ & $(.090)$ & $(.048)$ \\
of deviations from trend & $.734 *$ & $.710 *$ & $.750 *$ & $.846 *$ \\
& $(.277)$ & $(.133)$ & $(.106)$ & $(.050)$ \\
\end{tabular}

Note: Standard errors are reported in parentheses. * Significant at the 95 percent level. 
Several authors ${ }^{16}$ have claimed that the random walk model of the real exchange rate has a basis in efficient markets theory. Their argument is apparently that if the expected inflation rate is lower in the United States than in Germany, allowing for expected exchange rate changes, then an arbitrageur can contract to buy automobiles in the United States and ship them to Germany and expect to sell them there at a higher price; such profitable arbitrage would then eliminate the opportunity to begin with, enforcing PPP in expected rate-of-change form. If this arbitrage is intended to be different from the old arbitrage in level form which has been empirically rejected, and these authors clearly intend it to be different, then it is a remarkable strategy to recommend to international traders. Measures of expected real depreciation of the dollar as of 1985 showed a short-term depreciation rate of about 1.0 percent per annum. As of 1985, the level of BMW prices was sald to be almost twice as high in the United States as in Germany, as a result of the five-year appreciation of the dollar against the mark. Yet the apparent strategy tells people to buy BMS in the United States and ship them to Germany because in the three months it takes to complete the shipment their relative prices will have increased 0.25 percent in expected value! The near-50-percent loss would seem to outweigh the 0.25 -percent gain.

Even though ex ante relative PPP has little basis in theory, it does appear to have some empirical support. Typically, the estimated speeds of adjustment during the floating rate period, .27 or .28 on an annual basis in Table 1 (1973-84), while not so low as to be implausible as point estimates, are nevertheless so low that one statistically 
cannot reject the hypothesis that they are zero. In other words, one cannot reject the hypothesis that the autoregressive coefficient is 1.0 .

A 95-percent confidence interval on the autoregressive coefficient covers the range 0.17 to 1.27 (in the no-trend case). If the null hypothesis is an autoregressive coefficient of 1.0 , one cannot legitimately use the standard t-test derived from a regression where the right-hand variable is the level of the real exchange rate, because under the null hypothesis its variance is infinite. There are a number of ways of dealing with this nonstationarity problem. Here we simply apply the corrected Dickey-Fuller (1979) cumulative probability distribution for the t-test appropriate for this problem. The t-ratio to test an autoregressive coefficient of 1.0 is 1.13 , which falls far short of the Dickey-Fuller 95-percent significance level, 3.00 .

This failure to reject a random walk in the real exchange rate is the same result found by Roll (1979), Frenkel (1981, p. 699), Darby (1981), Adler and Lehman (1983), Mishkin (1984, Pp. 1351-53) and Pigott and Sweeney (1985). Hakkio (1984) provides evidence of a unit root in the real exchange rate using the Dickey-Fuller (1979) statistical procedures. Most of these studies used monthly data rather than yearly, and the statistical procedures employed were generally not powerful enough to reject the random walk.17

A more promising alternative is to choose a longer time sample. Table 1 also reports statistics for the entire postwar period 1945-84. PPP held slightly better during the Bretton Woods years than it did after 1973, as measured efther by the mean absolute deviation and standard deviation of the real exchange rate, or by the ability to 
reject the hypothesis of zero autocorrelation. But, despite the longer time sample, one is still unable to reject the random walk. The 95percent confidence interval runs from .65 to 1.01 , and the $t$-ratio of 1.9 falls short of the Dickey-Fuller 95-percent significance level of 2.93 .

The last column of Table 1 presents an entire 116 years of U.S.U.K. data. With this long a time sample, the standard error is reduced considerably. The rejection of no serial correlation in the real exchange rate is even stronger than in the shorter time samples. More important, one is finally able to detect a significant tendency for the real exchange rate to regress to $\mathrm{PPP}$, at a rate of 14 percent a year. The confidence interval for AR runs from .77 to .95 , safely less than unity, and the t-ratio of 2.92 exceeds the Dickey-Fuller significance level of 2.89 .

If the speed of adjustment to PPP is indeed on the order of 20 percent a year, and the standard deviation of the real exchange rate is on the order of .15 , then the standard deviation of new shocks is on the order of $\sqrt{\left(1-.80^{2}\right)\left(.15^{2}\right)}=10$ percent. With such a large error term in the regression equation, it is not surprising that most econometricians have been unable statistically to reject zero adjustment using the data from a mere 14 years of post-1973 data. The tests simply have insufficient power. This conclusion is supported by Monte Carlo tests as performed by Hakkio (1986). He hypothesizes an ARIMA $(1,1,2)$ process for the real exchange rate (with the first-order autoregressive coefficient equal to .9) and manufactures 100 months of data. He finds that the standard tests are not powerful enough to reject the random walk. 18 
The problem distinguishing between a stationary and a random walk process can be considered by calculating an approximate value of sample size $N$ that would give rise to a 95 percent confidence interval for AR (the first order autoregressive coefficient) that excludes the value one. With a little hand-waving and the use of the conventional formula for the variance of the estimate of AR these values of $N$ would be roughly 156, 196, and 759 for actual values of AR equal to .95, .96, and .99 respectively. $\mathrm{N}=156$ is roughly the number of months in the modern floating rate period. In terms of the half-life of deviations from PPP it would take about 13, 16, and 68 observations (months) for 50 percent of the deviations from PPP to disappear, when AR for the real exchange rate was $.95, .96$ and .99 respectively.

Thus in our view the evidence for a unit root in real exchange rates is much less convincing than the evidence for a unit root in nominal exchange rates, suggesting that PPP is still a reasonable anchor for long-run exchange rate expectations.

The implications of the nonstationarity of the logarithms of nominal exchange rates and the near nonstationarity of the real exchange rate for tests of spot rate determination, forward rate bias, and variance bounds will be discussed at the appropriate places in the next three sub-sections respectively.

\section{Regressions of Exchange Rate Determination}

Regressions of equations of exchange rate determination were the first sort of tests to become popular in the mid-1970s. The flexibleprice monetary mode1, 19 for example, was represented by the equation 


$$
s_{t}=m_{t}-\phi y_{t}+\lambda\left(1-1^{*}\right)_{t}+u_{t} \text {, }
$$

where $s_{t}$ is the $\log$ of the spot exchange rate (domestic currency/ foreign), $m_{t}$ is the $\log$ of the domestic money supply relative to the foreign, $y_{t}$ is the $\log$ of domestic income relative to foreign, $(1-i *)_{t}$ is the interest differential, and $u_{t}$ is the regression error. The model is derived from the assumption of instantaneous adjustment and perfect substitutability in the goods market (implying purchasing power parity) as well as in the bond market (implying uncovered interest parity)..$^{20}$ Under the assumptions, $\left(1-i^{*}\right)_{t}$ could as easily be replaced by the forward discount $\mathrm{fd}_{t}$, or by investors' expected rate of depreciation $\Delta s_{t}^{e}$.

$$
s_{t}=m_{t}-\phi y_{t}+\lambda\left(\Delta s_{t}^{e}\right)+u_{t}
$$

Intuitively, an increase in the relative supply of the domestic currency $m_{t}$ will lower its value, or raise the price of foreign currency $s_{t}$. Anything that raises the relative demand for domestic currency, 11ke an increase in relative income $y_{t}$ or a decrease in expected future capital losses $\Delta s_{t}^{e}$, will have the opposite effect. Other authors argued that important elements were missing from the equation. As we saw in the last section, deviations from purchasing power parity are in fact very large. If they were purely random, they could just be subsumed in the regression error $u_{t}$ (as could random shifts in money demand). But we also saw that they are in fact highly autocorrelated. If the deviations are thought to have an autocorrelation coefficient of 1 , 1 .e., if the real exchange rate is 
thought to follow a random walk, we have the version of the monetary model used by Meese (1986). The equation could simply be estimated on first differences. On the other hand, if deviations from PPP arise primarily from price level stickiness and thus are thought to be damped over time, e.g., to follow an $A R(1)$, and if expectations correctly reflect this tendency to return to long-run equilibrium, then a more complete model is needed. The real interest differential, which is equal to expected real depreciation, will be proportionate to the current deviation from equilibrium..$^{21}$ In the sticky-price monetary model, 22 we can simply add the real interest differential $\left(i-\pi^{e}\right)-\left(i^{*}-\pi^{*}\right)$, to equation $(8)$ : When the interest differential rises without a rise in expected inflation $\left(\pi^{e}\right)$, it attracts an incipient capital inflow that causes the currency to appreciate. The coefficient is $1 / \theta$, where $\theta$ is the expected rate of adjustment of the spot rate to equilibrium.

Another alternative to the simple monetary model is the portfolio-balance model ${ }^{23}$ which relaxed the assumption of uncovered interest parity, and as a consequence introduced the stocks of bonds into the model. Some synthesis versions required only adding a variable for the cumulation of government deficits and current account deficits to the earlier equations. 24

These models have all been grouped under the name "asset market approach" because they all assume that exchange rates are determined in financial markets in which investors are able to shift their asset holdings instantaneously. It is important to note that the models already build in a high degree of exchange rate volatility, even without 
any special factors such as irrational expectations, speculative bubbles, or an error term. In the flexible-price monetary model, for example, a one percent change in the money supply will have a more-thanproportionate effect on the contemporaneous exchange rate, if it leads investors to expect more money growth and currency depreciation in the future. (This has been called the magnification effect.)

In the sticky-price overshooting model of Dornbusch, even a onetime change in the money supply can have a more-than-proportionate effect, because it transitorily lowers the interest rate and as a result drives the value of the currency below the new long-run equilibrium level. 25 Sometimes, especially in policy circles, the overshooting model has been mistakenly invoked to support the idea that irrationality or speculative bubbles increase exchange rate variability. But most readers of the Dornbusch paper have realized that its beauty lies precisely in the fact that overshooting occurs even when investors behave well in the sense that their speculation equates the forward discount to the rationally expected rate of depreciation. Indeed, when expectations are rational in the Dornbusch model, the conditional variance of the spot rate is given by

$$
\left(1+\frac{1}{\lambda \theta}\right)^{2} \sigma_{\varepsilon}^{2}
$$

where $\sigma_{\varepsilon}^{2}$ is the variance of changes in the money supply. ${ }^{26}$ There is a sense in which this much volatility, if not necessarily optimal for the allocation of resources (a question on which we have demurred), is a natural and inevitable consequence of money supply changes in a stickyprice wor1d. 
The econometric evidence from regression tests can only be interpreted as saying that either expected depreciation is not adequately captured by the forward discount (or interest differential), or else there is some other substantial error term a in an equation like (8) that will enter the variance of $s$ in addition to the fundamentals variables. One can always postulate the existence of variables that must have been incorrectly omfted, as the real interest differential would be if the sticky-price monetary model is correct but equation (8) is tested without it. But it is fair to say that every equation that has been proposed, or that is likely to be proposed in the future, has a substantial error term left over. Much has been made (appropriately) of the models' inability to predict out-of-sample. But many of the regression estimates have shown very poor fits, not to mention unsensible coefficients, within the sample period as well. Even for the sample period during which the sticky-price monetary model fit the mark/dollar data remarkably well, the $\mathrm{R}^{2}$ was only .80 .27 Subsequent sample periods usually showed less sensible coefficients and worse fits for all varieties of models (except when a lagged endogenous variable is used. In such cases a more informative goodness of fit statistic would be one that measured the contribution of the explanatory variables after accounting for the past history of the spot rate.) ${ }^{28}$ Unsensible coefficients are often attributable to endogeneity of righthand side variables. For example, negative coefficients on the money supplies can be attributed to central bank reaction to the exchange rate when setting monetary policy. Income, interest rates and other variables are also almost certainly endogenous .29 Unsensible 
coefficients would in turn explain the inability to predict even directions of movement out-of-sample. Such econometric problems have encouraged many to go on to other testing procedures, such as those discussed in later sections. But it is important to note at this stage that the endogeneity problems alone cannot explain the poor fits. To see this, one need not rely on instrumental variables estimates, which are only as good as the instruments used. One can impose a unit coefficient on the money supply and reasonable values on the other coefficients; the fits are still poor.$^{30}$ In the limit, if the error term $u_{t}$ in the regression were indeed always close to zero, one should get a perfect fit regardless of whether the righthand-side variables are determined in other equations. This is true even if sophisticated theories of the expectations term are built from rational expectations, speculative bubbles, etc. Assuming expected depreciation is measurable by the forward discount, then some function of the forward discount and other fundamentals should give a good fit, unless there are large omitted factors.

Why emphasize so much the poor fits? The first reason is it already gives us our first conclusion: no set of macroeconomic variables that has been proposed is capable of explaining a very high percentage of the variation in the exchange rate. One can always postulate, in the manner of "real business cycle theory" some unobservable portfolio shifts or productivity shocks that must be determining the exchange rate. But if the shocks cannot be measured or even described meaningfully, then they probably belong in the error term $u$. Our conclusion that the magnitude of $u$ is large is evidence, for example, 
undermining any defense of exchange rate variability made on the grounds that it is appropriate given changes in monetary policy. If all exchange rate changes were in truth explainable by changes in money supplies, either contemporaneous or anticipated, we would have much better results in our regressions of the monetary equation (1) than we do. The second reason why we flag here the poor fits and simultaneity problems is that some of the alternative tests that econometricians have turned to, though seemingly more sophisticated than these regressions, are very sensitive to the assumed behavior of the error term. These are the variance-bounds and bubbles tests, which are discussed in section II .4 below.

Faced with poor econometric results for our models based on macroeconomic fundamentals, the proper response is to test components of the models in isolation. (It is not to test the models jointly with other assumptions!) Tests of unbiasedness in the forward market are one such approach, as almost all of the models include rational expectations as a key element, or at least as a special case. They are also thought to shed light on the question whether the forward discount can legitimately be used to measure expected depreciation. We now turn to these tests.

\section{Interpreting Tests of Blas in the Forward Discount}

The literature testing the unbiasedness of the forward discount is by now truly voluminous. Typically, the ex post error made by the forward discount in predicting the change in the spot rate is regressed against information available at the beginning of the period, such as 
the lagged prediction error..$^{31}$ It often turns out that a statistically significant portion of the prediction errors can be explained using the available information, which constitutes a rejection of the null hypothesis of unbiasedness.

The most common test in this literature takes the forward discount itself to be the information set on which expectations are conditioned .32 The regression equation is

$$
\Delta s_{t+1}=a+b f d_{t}+\varepsilon_{t+1}
$$

Under the null hypothesis that the forward discount is an unbiased predictor of actual depreciation, the coefficient $b$ should be one. 33 It is important to consider tests of the bias in the forward rate in difference rather than levels form. Earlier versions of the test regressed the level of the realized future spot rate against the level of the forward rate. ${ }^{34}$ The argument in favor of the difference versions of the forward rate bias test can be made as follows. Since the logarithms of the levels of spot and forward rates contain unit roots, each of these series are highly autocorrelated. In addition, the sample contemporaneous cross correlation of the $\log$ levels of spot and forward rates is essentially one, over any subset of the modern floating rate period. This common stochastic trend in the $\log$ levels of spot and forward rates ensures that they are highly cross-correlated, even when the two series are sampled at slightly different points in time. Finally, the sample variance estimates of the $\log$ levels of spot and forward rates are essentially the same over any subset of the recent floating rate period. These "empirical regularities" guarantee that the 
slope coefficlent from a regression of $s_{t+l}$ on $f_{t}$ will be near unity, as this coefficient is equal to the sample correlation coefficient when the variables have the same sample variance. In modern time series parlance, the log levels of spot and forward rates are cointegrated with a cointegrating constant near unity. The set of empirical regularities that suggests the levels regression will have a coefficient near one has no implications for either of the difference versions of the forward rate bias test. 35

The null hypothesis in equation (11) is usually rejected. The coefficient is significantly less than one; the implication is that one could expect to make money by betting against the forward discount whenever it is nonzero. Often the estimated coefficient is close to zero or even negative, which would say that the forward discount does not even get the direction of movement of the exchange rate right. Bilson (1981) interprets this finding as "excessive speculation:" investors would do better if they would routinely reduce toward zero the magnitude of their expectations of exchange rate changes. Most economists have not followed Bilson in the large step from the statistical finding of bias to the conclusion that the rational expectations hypothesis should be rejected. The economist's usual a priori argument--that any incipient opportunity for earning excessive profits would quickly attract investors who would eliminate it--is considered sufficiently strong that other explanations for the finding of bias are sought.

Easily the most common explanation given is exchange risk. Riskaverse investors will demand some extra expected return for taking an 
open position in a currency that they perceive as riskier. ${ }^{36}$ whether or not the optimal statistical predictor equals the expectation that investors have in mind (rational expectations), if the investors' expectation is not in turn equal to the forward rate (because of a risk premium separating them), then the forward rate will be biased. This explanation is discussed at some length in Part III.

Here we discuss two other explanations that are sometimes given for the finding of bias in the forward rate. One is easily covered. Under the joint null hypothesis of rational expectations and risk neutrality, it is expected real profits that should be zero; but the condition usually tested is the absence of expected nominal profits. The reason for the distinction is not that goods price indices are different in different countries. The same price index, determined by whatever consumption basket is relevant for the investor in question, should be applied to both currencies. The problem is rather that the price index goes in the denominator of the expression for the expected real value of an asset, and by Jensen's Inequality it does not drop out of the expected difference in returns on countries' assets. (This is the resolution of the famous "Siegel's Paradox;" see Frankel and Razin (1980), Engel (1984) or the references cited in these papers for a more complete explanation.) Doing the tests in real terms rather than nominal does not seem to make much difference however. This is what one would expect from the fact that the short-term variability of goods prices is much smaller than the variability of exchange rate; presumably it is also true that uncertainty regarding goods prices is much smaller than uncertainty regarding exchange rates. Indeed, in the special case 
where goods prices are nonstochastic when expressed in the currency of the producer country and the spot rate is distributed log-normally, the usual method of running the regression on logs of the nominal spot and forward rate is exactly correct. 37

A more serious obstacle to interpreting findings of forward rate bias as evidence against the joint hypothesis of rational expectations and risk neutrality is the "peso problem." As is widely known by now, the peso problem arises when there is the possibility of a large depreciation in the currency contingent on an exogenous event that may not have occurred in the sample period. In the context of the surprisingly sustained period of dollar appreciation in the early 1980s, wth the forward market all the while forecasting a depreciation, it has been suggested that either the collapse of a rational speculative bubble or a sudden shift in the fiscal and monetary policy mix could be such an exogenous event. Unfortunately, the term "peso problem" is sometimes used indiscriminantly to explain away any rejections of unbiasedness, leaving one to wonder why the test is run in the first place. It is important to remind ourselves of the familiar fact that standard statistical significance tests take into account the possibility of an event by chance failing to occur in the sample. (This assumes that the sample period was dictated by exogenous considerations such as data availability, as is the case in most of the tests.) One cannot say, for example, that "the forward market repeatedly mis-forecast the appreciation of the dollar in 1981-84 because it could not know that the White House or Congress would repeatedly fall to correct the structural budget deficit." If investors repeatedly mis-forecast fiscal policy in the 
same direction, that itself is a violation of the rational expectations hypothesis.

The correct definition of the peso problem is that, because of the possibility of a discretely-large change in the exchange rate, a usually-respectable number of observations might not in fact be large enough to give an approximately normal distribution to the coefficient estimate, with the result that the usual significance levels applied to the t-statistic may be inappropriate..$^{38}$ When one suspects that such a failure of normality may be a problem, one response is to use tests that do not require that distributional assumption. Nonparametric tests of the dollar in the 1981-1985 period show that statistical rejections of unbiasedness need not necessarily depend on normality: the dollar repeatedly moved upward in value while the forward discount was predicting the reverse (Frankel (1985b), Evans (1986)). It is true, however, that nonparametric tests frequently depend on a random sampling assumption. If we leave behind Jensen's Inequality and the peso problem, the exchange risk premium remains the major explanation--short of a rejection of rational expectations--for the findings of bias in the forward rate. We will consider exchange risk, and the information to be gained from the theory of portfolio optimization, in Part III.

\section{Variance Bounds and Bubbles Tests}

Variance bounds tests have been found intuitively appealing for two reasons. First, they have the appearance of more generality than regression tests. Second, they appear to hook up neatly with the popular feeling--which is the main motivation of the present study--that markets have been in some sense too volatile. 
It has been pointed out repeatedly that the variance-bounds and bubbles tests require the assumption that the economic fundamentals have been correctly identified. Hamilton and Whiteman (1986) criticize the bubble tests on the grounds that "one can always relax restrictions on the dynamics of the fundamental driving variables so as to interpret what appears to be a speculative bubble as instead having arisen from rational agents responding solely to economic fundamentals not observed by the econometrician." Similarly, Meese (1986) and Flood, Hodrick and Kaplan (1986, p. 32) argue that the tests are actually tests of the joint hypothesis of (i) a correct model, (ii) no regime changes, and (iii) no bubbles.

These criticisms have also been levelled at the variance-bounds tests applied to the stock market by Shiller (1981). For example, Marsh and Merton (1986) argue that their assumption about the dynamic process governing the payout of dividends will result in a violation of Shiller's sample variance bounds even when the simple stock price present value is in fact true. But it has not entirely sunk in, for the case of the foreign exchange market, how damaging is the dependence of the tests on having correctly specified the macroeconomic fundamentals. (The same could be said for specifying the money demand function correctly in tests of hyperinflation.) In the case of the stock market, at least modelling the price as the present discounted value of expected future dividends is fairly airtight, subject only to the possible problem of a risk premium. 39

We now spell out briefly the steps in deriving a bubbles test, starting from a model such as equation (9), and the perils that lie 
therein. If agents are assumed to have rational expectations, $\Delta_{t} e$ can be replaced by $E_{t}\left(s_{t+1}-s_{t}\right)$ in the equation:

$$
s_{t}=m_{t}-\phi y_{t}+\lambda\left(E_{t} s_{t+1}-s_{t}\right)+u_{t}
$$

Equation $\left(9^{\prime}\right)$ could be estimated by McCallum's (1976) method of replacing $E_{t} s_{t+1}$ by the expost realization $s_{t+1}$ plus a random prediction error $\varepsilon_{t+1}$ and then using an instrumental variables (IV) technique such as Generalized Method of Moments or two-step two-stage least squares. Alternatively, if the regression error $u_{t}$ were thought to be small relative to the expectational error $\varepsilon_{t+l}$, it would be preferable to solve for $s_{t+1}$ before estimating.

(g'' $) \quad s_{t+1}=\frac{1+\lambda}{\lambda} s_{t}-\frac{1}{\lambda} m_{t}+\frac{\phi}{\lambda} y_{t}-\frac{1}{\lambda} u_{t}-\varepsilon_{t+1}$

Equation $\left(9^{\prime}\right)$ or $\left(9^{\prime \prime}\right)$ will hold--under the joint hypothesis of rational expectations and the rest of the model--regardless whether there is a speculative bubble term or not.

To test the spectal case of no bubble, we estimate the model a different way. We solve for $s_{t}$ as a function of expectations:

$$
s_{t}=\frac{1}{1+\lambda} m_{t}-\frac{\phi}{1+\lambda} y_{t}+\frac{\lambda}{1+\lambda}\left(E_{t} s_{t+1}\right)+\frac{1}{1+\lambda} u_{t}
$$

We then note that

$$
E_{t} s_{t+1}=\frac{1}{1+\lambda} E_{t} m_{t+1}-\frac{\phi}{1+\lambda} E_{t} y_{t+1}+\frac{\lambda}{1+\lambda}\left(E_{t} s_{t+2}\right)+\frac{1}{1+\lambda} E_{t}\left(u_{t+1}\right)
$$

substitute into (12), and continue to substitute recursively. The wellknown result is that the (no-bubble) solution for today's exchange rate can be written as the present discounted sum of the entire expected 
future path of monetary conditions:

$$
s_{t}^{*}=\sum_{\tau=0}^{\infty}\left(\frac{\lambda}{1+\lambda}\right)^{\tau}\left(\frac{1}{1+\lambda}\right) E_{t}\left(m_{t+\tau}-\phi y_{t+\tau}+u_{t+\tau}\right) .
$$

For example, if far-sighted agents expect an increase in the money supply to take place four years in the future, it will have an effect on the exchange rate today. The reason is that they expect the currency to depreciate (whether in terms of goods or foreign currency) in four years, and thus expect that agents in three years will seek to move out of domestic currency in anticipation of capital losses, causing a depreciation in that period. Agents in two years will in turn seek to move out of domestic currency, and so on. The depreciation is passed all the way back to the present.

Note that setting the price of foreign exchange to the present discounted sum of expected future monetary conditions (where the discount factor is $1 /(1+\lambda)$ ) is analogous to the model in the stock market that sets the price of equity to the present discounted value of expected future dividends (where the discount factor is one over one plus the real interest rate). The major difference is that we are much less confident about having the right fundamentals in the foreign exchange market. In addition, estimation of equation (13) requires that the disturbance term $u$ be uncorrelated with the appropriately dated fundamentals (or else an IV procedure must be utilized ${ }^{40}$ ).

Equation (13) gives only the particular fundamentals solution, which sets the coefficient on the speculative bubble term to zero. The intent of the bubbles tests is to test the equation against the alternative more general solution 
(14) $\quad s_{t}=s_{t}^{*}+\left(\frac{1+\lambda}{\lambda}\right)^{t} a_{t}$

where $a_{t}$ is any stochastic process satisfying $E_{t} a_{t+\tau}=a_{t} \cdot$ The extra term can arise from self-fulfilling expectations: if everyone expects the dollar to appreciate, even if for a reason unrelated to fundamentals ("sunspots"), they will buy dollars and drive up the price, so that the expectation turns out to have been rational. In a single deterministic bubble of the sort Flood and Garber (1980) test for, $a_{t}$ is a constant. But there are other possibilities. In the stochastic bubble model of Blanchard and Watson (1982) ${ }^{a_{t}}$ has a probability of collapsing to zero each period.

The next step in the bubbles tests of West (1984), Meese (1986) and Casella (1985) is a non-trivial assumption in any context: some stable dynamic process must be assumed for the fundamentals variables $\mathrm{m}_{t}$ and $\mathrm{y}_{t}$, such as a vector autoregression. Then the Hansen-Sargent (1980) prediction formula can be applied to (13) so that the expected future values of $m_{t}$ and $y_{t}$ are substituted out. This results in a multiple equation system with nonlinear cross equation constraints that we shall refer to as (13').

The trick behind the bubbles test is the recognition that under the null hypothesis of "no bubble term" the estimator of the parameters of equations (13') will be more efficient than the estimator of the parameters of equation ( $\left.9^{\prime}\right)$. Under the alternative hypothesis that there is a bubble term as in equation (14), the estimator of the parameters of equation ( $\left.9^{\prime}\right)$ will still be consistent, whereas the estimator of the parameters of equations (13') will be inconsistent. 
Thus a Hausman (1978) specification test can be used to choose between the two possibilities.

At least four propositions are being maintained when estimating the system (13'); (a) the macroeconomic model such as equation (8) is correct, (b) the interest differential or forward discount is an unbiased predictor in the sense of equalling the realization within the sample period, up to a random prediction error (this requires rational expectations, no peso problem or regime changes, and no risk premium), 41 (c) there are no bubbles, and (d) the dynamic model assumed for the explanatory variables is correct. (The last assumption can be checked independently using standard procedures.) Assumptions (a) and (b) are also maintained when estimating $\left(9^{\prime}\right)$. Thus the bubbles test procedure only makes sense if diagnostic checks of the estimated fit of $\left(9^{\prime}\right)$ do not indicate misspecification. Testing propositions (c) and (d) while maintaining (a) and (b) has the obvious difficulty that if the null hypothesis is rejected one does not know why. But in the present context, it seems particularly tenuous, since propositions (a) and (b) can be tested individually, and few people interpret the evidence as supporting them.

In addition, the small sample properties of the bubble specification test have been questioned (In the context of the present value relation for stock prices) by Mattey and Meese (1987). In their simulation experiments the nonparametric tests for bubbles turned out to be much more reliable tests for the presence of bubbles than the specification test. Evans (1986) has employed nonparametric tests of bubbles 
on the dollar-pound exchange rate over the recent floating rate period, and reports finding a bubble in the dollar-pound rate.

We now consider the weaknesses of variance bound tests. We repeat equation ( 1 ), or its incarnation as the monetary model equation (9), as

$$
\mathbf{s}_{t}=\ell_{t}+B\left(\mathbf{s}_{t+1}^{\mathbf{e}}-\mathbf{s}_{t}\right)
$$

where $\beta$ is the sensitivity of the current spot rate to the expected change in the spot rate (the same as $\lambda$, the semi-elasticity of money demand, in the monetary model), and $\ell_{t}$ denotes all the fundamentals. Now the results from Meese and Singleton (1983) allow us to deduce

$$
\operatorname{var}\left(s_{t}\right) \leq \operatorname{var}\left(e_{t}\right),
$$

In the absence of exchange market bubbles. Here $\ell_{t}$ can include the structural disturbance $u_{t}$ in (1) or the variance bound can be taken after projecting $s_{t}$ and $\ell_{t}$ on an information set that excludes ${ }^{u_{t}}$. The variance bound in (15) can be written in terms of conditional variances or, if equation ( $\left.9^{\prime}\right)$ holds in first differences with $u_{t}$ as the structural disturbance, then a bound analogous to (15) holds for the first difference of $s_{t}$ and $\ell_{t}$. Thus nonstationarity of the exchange rate or fundamentals will not undermine the following discussion. The relation (15) makes it clear that it is meaningless to compare the variability of $s_{t}$ with an individual component of $\ell_{t}$ unless $l_{t}$ contains a single variable, or we know all the values of the structural parameters on the variables in $\ell_{t}$ and the covariances between all the fundamentals. Actual variance bounds tests of (1) are 
generally uninteresting because they test whether the variance of a linear combination of the variables in $\ell_{t}$ is an upper bound on the variance of $s_{t}$, and the tests are conditioned on knowing the correct variables and the correct values of the structural coefficients. While it is true that the Generalized Method of Moments (GMM) methodology of Hansen (1982) can be used to construct a statistical test of (15) that incorporates the sampling variability of the estimated parameters, this has not been done in the exchange rate context. We believe that such an exercise is futile since it is already known that asset market models of exchange rate determination fit poorly.

A more obvious problem with variance bounds tests can be seen from the application of variance bounds procedures to tests of forward rate bias. Recall that the unbiasedness equation

$$
\begin{aligned}
& \Delta s_{t+1}=a+b\left(f d_{t}\right)+\varepsilon_{t+1} \text { with } b=1 \text { implies } \\
& \operatorname{var}\left(\Delta s_{t+1}\right) \geq \operatorname{var}\left(f d_{t}\right) .
\end{aligned}
$$

The variance bounds test has no power to detect the alternative $\operatorname{cov}\left(\mathrm{fd}_{t}, \varepsilon_{t+1}\right)=\operatorname{cov}\left[\mathrm{fd}_{t},\left(\mathrm{~s}_{t+1}-\mathrm{f}_{t}\right)\right]>0$, since (17) would hold $a$ fortlori. The most common empirical finding in regression tests of (16) is that $\operatorname{cov}\left(\Delta s_{t+1}, f d_{t}\right)<0$ which also implies that $\operatorname{cov}\left(f d_{t}, \epsilon_{t+1}\right)<0.42$ However, the variance of the lefthand side of (17) is typically so much larger than the variance of the righthand side that a test of (17) fails to uncover a significant negative covariance of the forward discount with the forecast error $\varepsilon_{t+1}$. For example, take the published results in thang (1984). His regression tests of (16), reported in his Table 1 (p. 157), indicate two rejections of $b=1$ when $\hat{b}<0$ and one 
rejection of $b=1$ when $\hat{b}>0$, out of a total of nine currencies. In his following Table $4(p \cdot 160)$, none of the variance bounds tests reject (17) for the same currencies and sample periods. It is true that all of Huang's point estimates of the bound

$$
\operatorname{var}\left(\Delta s_{t+1}\right) \geq \operatorname{var}\left(\varepsilon_{t+1}\right)
$$

are violated, but none of the violations is statistically significant. These "small sample" results illustrate the large-sample theoretical results of Frankel and Stock (1987) who show that the most powerful conditional volatility test is equivalent to the analogous regression test in terms of asymptotic power. See also froot (1987).

Finally, we conclude this section by noting that it is the lower variance bound on the forward rate (or forward discount) that is violated in exchange markets, not the upper bound. Properties of conditional variances allow us to deduce $\operatorname{var}\left(\mathrm{f}_{t}\right)>\operatorname{var}\left(\hat{\mathrm{s}}_{t}\right)$ where $\hat{s}_{t}$ is the predictor of $s_{t}$ based on the limited informatin set of past spot rates. The forward rate is the predictor of the spot based on the market's larger information set. (The regression analogy is that $R^{2}$ cannot decrease when you add explanatory variables.) Since the variance of the prediction error from forecasting $s_{t}$ on just its own past value is less than the variance of the prediction error from forecasting the spot rate with $f_{t}$, the market's forecast, the lower variance bound on the forward rate is violated. (See for example the root mean square error statistics in Meese and Rogoff (1983a) for the forward rate versus the random walk model as predictors of future spot rates and the other results discussed in section II.3.) 


\section{The Exchange Risk Preniun}

We are interested in the size and variability of the risk premium for two reasons. First if the size and variability are thought to be small, as argued in Frankel (1986a), then it is difficult to attribute the results of regression tests of forward rate unbiasedness (described in section II.3), or the results of variance bounds tests (described in section II.4), to the risk premium. This would leave only the explanation that expectations cannot be assumed rational (in the sense of lending themselves to representation by the ex post sample distribution).

Even if expectations are thought to be rational, there is a second motivation for looking at the variability of the risk premium. Since the risk premlum, $r p_{t}$ in equation (2), together with the substitutability parameter $B$, can be a key determinant of the exchange rate, estimating the variability of the risk premium will help us analyze the sources of variability in the spot rate $s_{t}$. Here we will be particularly interested in the effects on $s_{t}$ when there is an exogenous change in asset supplies $\ell_{t}$, expectations $\Delta s_{t}^{e}$, or the substitutability parameter $B$.

Until relatively recently, empirical work on the risk premlum was limited almost entirely to the estimates of bias in the forward market's prediction of future spot rates discussed in section II.3. The problem was that rational expectations had to be assumed a priori in order to interpret the systematic component of the prediction errors as equal to the risk premium. For those who were willing to make that assumption, 
the conclusion was that the risk premlum is large and variable. For example, the finding of zero coefficients in the regression of exchange rate changes against the forward discount implied that the rationally expected rate of depreciation was zero (random walk), and 100 percent of the forward discount was made up by the risk premium, rather than by expected depreciation. Since the dollar's forward discount against the mark or yen has moved over a range of roughly 2 percent to 4 percent in recent years, this would imply that the risk premlum was substantial in both magnitude and variability.

It has been argued that if the systematic component of the prediction errors is indeed properly interpreted as the risk premtum, then it ought to be related statistically to those variables on which theory tells us that the risk premium depends. We now turn to the theoretical determinants of the risk premlum and the corresponding econometric tests.

\section{Implications of Portfolio-Optinization with Constant Variance}

If investors maximlze single period utility that is a function of mean and variance of end of period wealth, asset demands can be written as a linear function of expected relative rates of returns:

$$
\mathbf{x}=\mathrm{A}-\mathrm{B} \mathrm{rp}
$$

where $B^{-1}=\rho \Omega$ and $A$ is the minimum variance portfolio. The parameter $\rho$ is the coefficient of relative risk aversion and $\Omega$ is the variance (covariance matrix in general) of exchange returns. Several authors 43 have inverted equation (3') without imposing the 
theoretical restrictions of mean-variance analysis, and have attempted to explain the ex post risk premium (forecast errors) by variables to which portfolio balance theory says that the risk premium should be related. This line of research has uniformly found no relation between $r p$ and $x$. The difficulty in predicting ex post risk premiums by asset shares can be appreciated by inspecting figures 1-5, where the two variables are plotted for five currencies versus the dollar over April 1973 to December 1984. The mean drifts in the Japanese, German, French and British shares are not accompanied by mean drifts in the corresponding excess return variables.

Using the constraints implied by mean-variance analysis, and reasonable coefficient estimates for the parameters in (3') Frankel (1986a) has argued that the exchange rate risk premium (and also its variability) must be very small. The argument can be summarized as follows: the unconditional monthly variance of the relative return on dollars over the period August 1973 - August 1980 is roughly .001 . If we take .001 as an upper bound on the conditional variance of relative dollar returns, and a coefficient on risk aversion equal to two, then

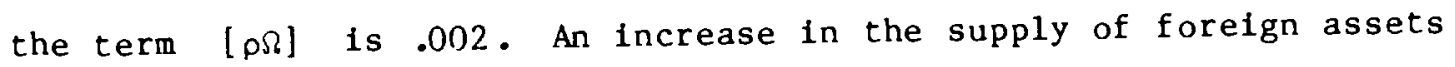
equal to $1 \%$ of the portfolio would only require an increase in the risk premium of 2.4 basis points on an annual basis! 44 The argument does, however, assume that the conditional variance of returns is constant; we take up this subject in the next subsection.

Hansen and Hodrick (1983), and Hodrick and Srivastava (1984, 1986), among others, have attempted to conduct inference regarding the magnitude and variability of the risk premium using a more general 
intertemporal utility valuation model of the risk premium. In this setting a linear equation relating asset suplies to the risk premium would only obtain if investors' preferences were logarithmic or asset returns are intertemporally independent. We would not a priori expect to be able to explain the risk premiun by relative asset shares alone, so these models offer an alternative theory of $r p$.

The intertemporal general equilibrium model of Lucas (1982), as amended by Hodrick and Srivastava (1984), can be used to derive a relation between the forward rate and the expected future spot rate. While this model relies on some very restrictive assumptions, it provides considerable insight into the nature of the exchange rate risk premium. In this type of individual utility maximization model the equilibrium price of an asset is found by equating the foregone marginal utility from purchasing an asset to the conditional expectation of the present discounted value of the marginal utility of return from holding the asset. In order to price a nominal forward exchange contract, money is introduced into the asset pricing model by the restriction that agents purchase a country's idiosyncratic endowment with that country's money. Arbitrage ensures that the next period forward price of foreign exchange be equal to the expected present value of a known return at time $t$ of investing in a nominally risk free bond with payoff in period $t+l, i_{t}$, multiplied by the spot rate that will prevail in the next period, $s_{t+1}$. The asset pricing model provides the interpretation of the discount factor as the intertemporal marginal rate of substitution (Richard and Sundaresan (1981)) between period $t$ and $t+1$ dollars, $t_{t+1}$, where, for convenience, a U.S. perspective has been 
adopted. Thus the forward rate can be written as:

$$
\mathbf{f}_{t}=E\left[t_{t+1}\left(s_{t+1}\right) i_{t} \mid I_{t}\right] .
$$

Using the definition of conditional covariance, (18) may be rewritten as:

$$
\mathrm{f}_{t}=E\left[s_{t+1} \mid I(t)\right]+\operatorname{cov}\left[t_{t+1}{ }^{1}, s_{t+1} \mid I_{t}\right]
$$

where $\operatorname{cov}\left[., . \mid I_{t}\right]$ denotes covariance conditional on the information set $I_{t}$, and the derivation of (19) makes use of the first order condition for utility maximization $E\left[Q_{t+1}{ }^{i} \mid I_{t}\right]=1$. The second term on the righthand side of (19) has the interpretation of a risk premium. However, it is useful to introduce a benchmark return, $i_{t+1}^{B}$, defined explicitly in Hansen and Hodrick (1983), so that (19) can be rewritten as a conditional capital asset pricing equation (CAPM):

$$
E\left(f_{t}-s_{t+1} \mid I_{t}\right)=B_{t} E\left(i_{t+1}^{B}-i_{t} \mid I_{t}\right)
$$

where $\beta_{t}$ is the conditional covariance of the risk premium and benchmark return divided by the conditional variance of the benchmark return .

Implications of this model have been tested by Hansen and Hodrick (1983), Hodrick and Srivastava (1984, 1986) and Cumby (1986), among others. Enpirical work is typically conducted assuming that conditional second moments and/or $\beta_{t}$ do not vary across time. While statistical tests of the "consumption beta" model usually indicate a rejection of the model, qualitative features of the data are explained by this paradigm; see the discussion in aumb (1986). We now turn our attention to 
the implications of time variation in return second moments on variability of the risk premium and in turn on the variability of the spot rate.

\section{Implications of Iime-Varying Return Oovariances}

A number of authors have in effect argued that the assumption of a constant covariance matrix of exchange returns should be relaxed. 45 Pagan (1986) argues, in a context where the conditional variance changes over time, that there may be some points when it exceeds the sample variance ( .01 on an annual basis), and that the risk premium at such a point will exceed the upper bound claimed in Frankel (1986a). But if we allow the conditional variance to vary over time, then one can still apply the upper bound to the average conditional variance and therefore to the average risk premium. If the conditional variance is 10 times larger than .0l one period in ten (for example, when the preceding squared realization was particularly large), then it is true that a one percent change in the portfolio in that period will change the risk premium by as much as 0.2 percent per annum, and that the magnitude of the risk premtum could be as large as 20 percent annum (if close to 100 percent of the portfolio is in one asset or the other). But in the other nine periods out of ten, these magnitudes would have to be zero for the variance to average out to .01 .

When we allow for return variances to vary over time, variation in the risk premium derives from this additional source and can thus exhibit considerable volatility. This point is made by Giovannini and Jorion (1986). If we are interested in the question of how big an effect foreign exchange intervention has on average, then the 
observation that the conditional variance and the risk premium may at times be higher and at times lower may not be very relevant. But for other questions, such as explaining the variability of the exchange rate, the observation that the risk premium changes over time is quite relevant.

Recent work by Cumby and Obstfeld (1984), Hsieh (1984), Domowitz and Hakkio (1985), and Giovannint and Jorion (1987a), rejects the hypothesis that the conditional variance of exchange returns is constant over time. Supporting evidence is provided by implicit variances extracted from options data in studies by Lyons (1986) and Hsieh and Manas-Ant on (1986): these estimated variances, which are to be thought of as characterizing investor's conditional beliefs, clearly vary over time.

Giovannini and Jorion (1987a) specify the conditional variance as a function of the levels of domestic and foreign interest rates. Their aim is to argue that their estimate of variation in the conditional variance corresponds to large variation in the risk premium, in contrast to Frankel (1986a). But they appear to have fallen into a (remarkably common) pitfall in their calculations: their estimates imply a true variance of the monthly risk premium equal to $1.1 \times 10^{-4}$, not 1.1 (Giovannini and Jorion, 1987b).

Perhaps the most popular approach to modeling the conditional variance of returns is to employ variants of Engle's (1982) autoregressive conditional heteroskedasticity (ARCH) process. In the context of the single period mean-variance model, Engel and Rodriguez (1987) show how to extend the econometric procedure of Frankel (1982) to 
account for time variation in return second moments. However, the basic message for the relation between asset shares and the risk premium is unaltered when the Engel-Rodriguez procedure is employed.

Table 2 provides evidence of the variability in exchange return second moments; the maximum, minimum, and average values of the sample standard deviations and correlations are tabulated for a sample of 100 months. The autocorrelation function of the annualized standard deviation of exchange return calculated from the \$/DM rate is displayed in Table 3. The pattern of autocorrelations in Table 3 is typical of all 21 elements in the second moment matrices displayed in Table 2. A reasonable characterization of this process is simple exponential smoothing or an ARIMA $(0,1,1): 46$

$$
\sqrt{\Omega_{t}}-\sqrt{\Omega_{t-1}}=\Omega_{0}+\delta_{t}+\theta_{1} \delta_{t-1} \text { with } \hat{\theta}_{1}=-.9 \text {. }
$$

The estimate of $\sigma_{\delta}^{2}$ varies by currency second moment, but $\hat{\theta}_{1}=-.9$ is robust to the series under analysis. The stochastic model (21) implies that all shocks $\delta_{t}$ to the standard error of exchange return second moments are permanent. The large negative coefficient on $\delta_{t-1}$ implies that after one period, the level of the standard deviation of return is increased by $10 \%$ of the initial shock forever. We are now ready to consider the implications of time variation in return second moments for the larger question of exchange rate determination. We can infer the effects of changes in exchange rate return variance on the demand for asset shares by looking at our equation for the optimally-diversified portfolio: 
Table 2

Exchange Rate Return Second Moments

\begin{abstract}
Monthly Exchange Returns Calculated from Daily Observations over the period December 1977 - April 1986

(Monthly return standard deviations run down the diagonal, and monthly correlations are displayed off the diagonal.)
\end{abstract}

The following entries are maximum values over the sample of 100 months:

$\begin{array}{lrrrrrr}\text { Australian Dollar } & 36.24 & & & & & \\ \text { British Pound } & .94 & 45.23 & & & & \\ \text { Canadian Dollar } & .81 & .85 & 14.80 & & \\ \text { German Mark } & .93 & .96 & .82 & 49.87 & \\ \text { Japanese Yen } & .93 & .93 & .77 & .96 & 23.78 & \\ \text { Swiss Franc } & .93 & .94 & .83 & .99 & .95 & 42.58\end{array}$

The following entries are minimum values over the sample of 100 months:

$\begin{array}{lllllll}\text { Australian Dollar } & 1.70 & & & & & \\ \text { British Pound } & -.46 & 2.42 & & & & \\ \text { Canadian Dollar } & -.46 & -.63 & .76 & & \\ \text { German Mark } & -.63 & -.42 & -.72 & 2.72 & \\ \text { Japanese Yen } & -.34 & -.65 & -.72 & -.21 & 2.74 & \\ \text { Swiss Franc } & -.47 & -.37 & -.65 & -.20 & -.04 & 3.02\end{array}$

The following entries are average values over the sample of 100 months:

$\begin{array}{lrrrrrr}\text { Australian Dollar } & 6.69 & & & & & \\ \text { British Pound } & .34 & 10.91 & & & & \\ \text { Canadian Dollar } & .19 & .25 & 4.03 & & & \\ \text { German Mark } & .37 & .60 & .26 & 11.06 & \\ \text { Japanese Yen } & .42 & .43 & .22 & .62 & 9.89 & \\ \text { Swiss Franc } & .39 & .58 & .27 & .81 & .63 & 13.07\end{array}$

Notes: A daily rate of return is defined as $(s(t)-s(t-1)) / s(t-1)$ for $t$ in the same month. All monthly return standard deviations are expressed as annual percentages and are calculated as if daily returns within a month constitute a random sample. 
Table 3

\section{Autocorrelation Functions for the Level and Difference of Return Volatility}

Level of Standard Deviation of \$/DM Annual Return: $\sqrt{\Omega}$ Mean of $\sqrt{\Omega}=11.06$ Sample Variance of $\sqrt{\Omega}=50.05 \quad$ Sample S1ze $=100$

\begin{tabular}{|c|c|c|c|}
\hline Lag & Autocorrelation & $\underline{\mathrm{Lag}}$ & Autocorrelation \\
\hline 1 & .14 & 7 & .14 \\
\hline 2 & .16 & 8 & .07 \\
\hline 3 & $.29 *$ & 9 & .05 \\
\hline 4 & .09 & 10 & .11 \\
\hline 5 & .07 & 11 & .02 \\
\hline 6 & .04 & 12 & -.03 \\
\hline
\end{tabular}

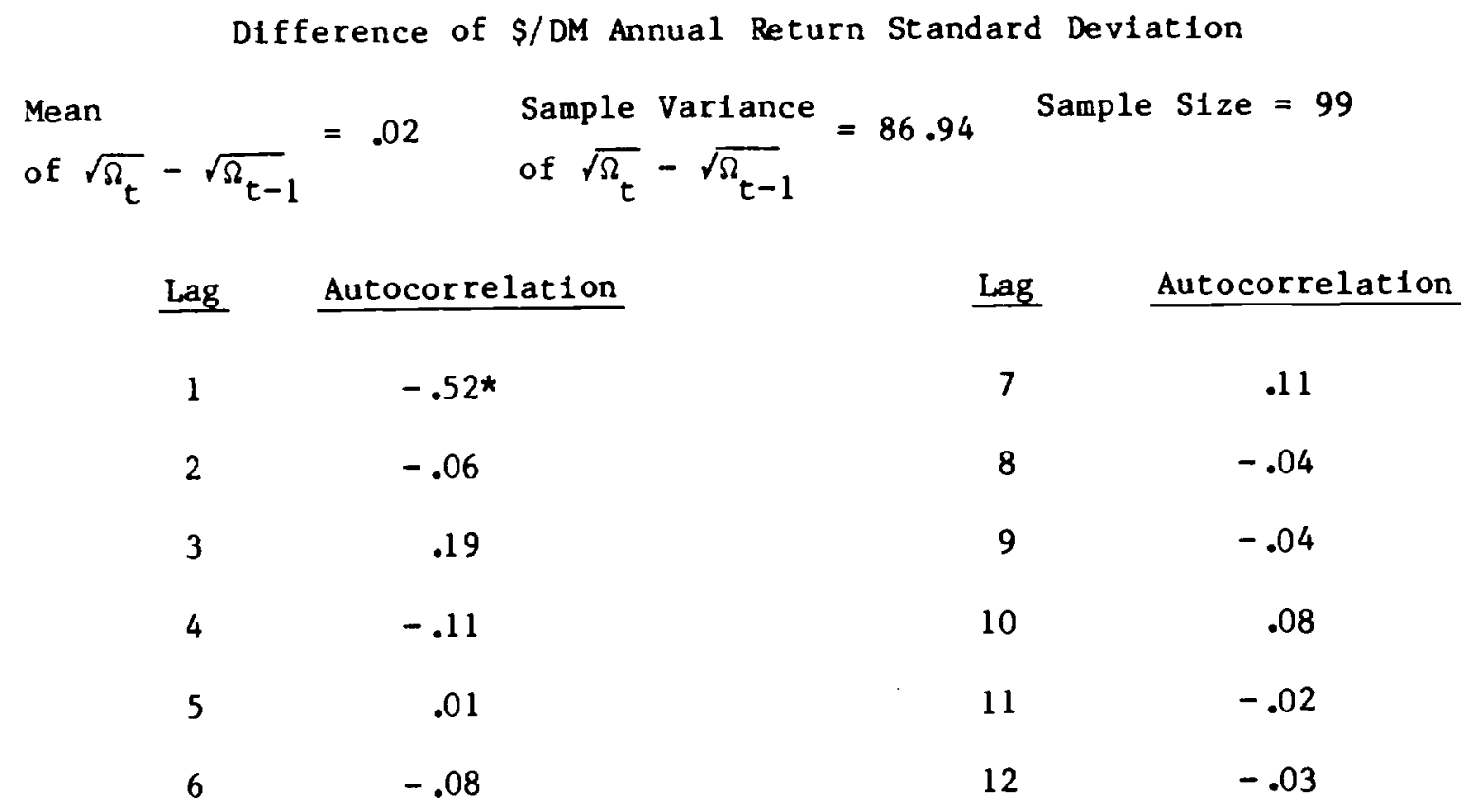

*denotes significance at a $5 \%$ level 
( $\left.3^{\prime}\right)$

$$
x_{t}=A-\left(\rho \Omega_{t}\right)^{-1} r p_{t}
$$

We will try several alternative cases regarding the assumed permanence of a change in the variance. Using equations (2) and (3') we can calculate first the effect on the spot rate of a once and for all change in the variance of exchange returns $\Omega_{t}$ 'holding the interest differential $i_{t}{ }^{*}{ }_{t}^{*}$ constant: $:^{47}$

$$
\left.\frac{d s_{t}}{d \Omega_{t}}\right|_{\left(1 t_{t}-i_{t}^{*}\right)-\left(s_{t+1}^{e}-s_{t}\right)}=+\left(\frac{1}{x_{t}}+\frac{1}{\left(1-x_{t}\right)}\right)\left(\frac{r p_{t}}{\rho \Omega_{t}^{2}}\right) .
$$

This analysis can be justified by assuming that the composition of monetary and nonmonetary assets is varied in whatever way is necessary to hold the interest differential constant. Since the change in $\Omega_{t}$ is permanent we know that the effect on tomorrow's spot rate will be the same as the effect on today's spot rate. Thus the risk premium $\left(i_{t}-1_{t}^{*}-\left(s_{t+1}^{e}-s_{t}\right)\right)$ is held fixed in this experiment. The analysis is in the same spirit as our earlier attempts to quantify loosely the effects of changes in the disturbance term $u_{t}$ in (2) and in expectations when macroeconomic fundamentals are held constant.

The sign of the effect, equation (22), of the return variance on the spot rate depends on the sign of the initial risk premium. If the foreign asset initially pays a positive risk premium over the domestic asset (because the supply that must be held exceeds the demand constituted by the minimum-variance portfolio $A ; r p_{t}$ as we have defined it is negative), then the permanent increase in uncertainty reduces the demand for foreign assets and thus reduces their price $s_{t}$. The effect 
on $s_{t}$ is zero if the initial risk premium is zero. But the effect can be very large in magnitude if the initial risk premlum is non-zero, for example if the initial risk premium is on the order of .03 (as it might be if the entire 3 percent discount at which the dollar sold against the mark or yen in the early 1980s is attributed to a risk premlum rather than to expected depreciation). For our benchmark parameter values $\left(x_{t}=1 / 2, \quad \Omega_{t}=.01\right.$ on an annual basis, and $\left.\rho=2\right)$, we can calculate the linearized effect on the spot rate $s_{t}$ of a change $\ln \Omega_{t}$ - Consider a permanent increase in the annual variance $\Omega_{t}$ from .01 to .02 . (One standard deviation of the monthly standard deviation for the \$/DM exchange return is estimated at roughly $9.3 \%$ per year over the December 1977 to April 1986 period in the bottom panel of Table 3; the square is .0087.$)$ Such a shock will have a possible linearized effect on $s_{t}$ of roughly $(-4)\left[\frac{.03}{2(.01)^{2}}\right] .01=-600 \%$, a large number. of course, permanent changes in $\Omega_{t}$ cannot occur very often. The autocorrelations in Table 3 are also consistent with the hypothesis that $\Omega_{t}$ is white noise around its mean. Under such a hypothesis no shocks are permanent. A purely transitory disturbance to $\Omega_{t}$ will have an effect which is very much smaller than that calculated above: calculations based on (22) are mitigated by the presence of a second term that arises because the spot rate is expected to go back to its previous level. 48

The results of this subsection suggest that additional research be directed at the spot rate-conditional volatility nexus. In appendix 1 we consider the model (21) for $\Omega$ as well as an ARCH process, in 
which the initial shock to the variance dies out gradually over time. The algebra is considerably more complicated than for the transitory disturbance, because there is a third effect, via the rational expectation of an effect on the spot rate next period, when the innovation to the variance will have only partially died out. The effect on the exchange rate lies between the effects of a permanent and transitory change in $\Omega_{t}$. (Poterba and Summers (1986) calculate the effect of variability in the variance of stock market prices on the level of stock market prices.) 49

\section{Survey Data and Heterogeneous Bxpectations}

of the factors suggested as determining "excessive variability" in section I of this paper, we have considered the role of fundamentals versus the disturbance term, and we have considered risk and the degree of substitutability. We have still to consider the role of expectations per se. The idea of destabilizing speculation--that investors, responding to non-zero expectations of exchange rate changes, work to raise the variability of the exchange rate--is what is often meant by descriptions of the market as excessively variable. The variance-bounds tests and bubbles tests at first sounded like a promising way to shed light on questions of destabilizing speculation and bandwagons. If we were confident about having specified the fundamentals correctly in equation (2), then we might look to the variance-bounds and bubbles tests to see if the expectations term $\Delta s^{e}$ is formed in a destabilizing way. More 
simply, we could compare the variance when $\Delta s^{e}$ in equation (9) is constrained to zero with the unconstrained variance: this is the test for "destabilizing speculation" performed by Kohlhagen (1979) and E1chengreen (1981). But, as we argued in section II, we are not at all confident about having specified the fundamentals correctly, which means that there is no new information to be gained from these tests.

At the end of Part I we suggested that the best way to get at the question of whether speculation is destabilizing or not is to consider whether expected future depreciation responds positively or negatively to a current change in the exchange rate. If a current depreciation, originating in fundamentals or in anything else, generates anticipations of further depreciation, speculators will sell the currency and thereby exaggerate the depreciation. If it generates anticipations of future appreciation, back in the direction of some long-run equilibrium, speculators will buy the currency and thereby dampen the depreciation. In this part of the paper we consider this question of how expectations are formed.

A way of defining stabilizing expectations is that the expected future spot rate $s_{t+1}^{e}$ gives a weight less than one to the contemporaneous spot rate, $s_{t}$, that it is a convex combination of the contemporaneous rate and other factors. We have the case of regressive expectations when the "other factor" is the equilibrium rate $\bar{s}_{t}$ :

$$
\mathbf{s}_{t+1}^{e}=(1-\theta) \mathbf{s}_{t}+\theta\left(\bar{s}_{t}\right)
$$

Or, in terms of expected depreciation,

$$
\Delta s_{t+1}^{e}=-\theta\left(s_{t}-\bar{s}_{t}\right)
$$


Stabilizing expectations are the case $0<\theta<1$, destabilizing expectations the case $\theta<0$, and the borderline case is static expectations, $\theta=0$.

\section{Measuring Stabilizing and Destabilizing Bxpectations}

Two alternative ways of measuring expected exchange rate changes are common in the literature. The first is the forward discount. The second is ex post changes in the sample period, allowing only for a purely random error term. The first is valid only if there is no timevarying risk premium, and the second only under the rational expectations assumption (including the absence of regime changes, peso problems, etc.).

When we use the rational expectations approach of substituting $\Delta s_{t+1}$ for $\Delta s_{t+1}^{e}$ in the above equation (23) and interpreting the regression error as a random expectational error, a test of $\theta=0$ is a test of a random walk in the true spot process, as in section LI. Table 4a, which is drawn from Frankel and Froot (1985), looks for a tendency of the dollar to regress toward equilibrium, where equilibrium is alternatively measured in rows $1-4$ by a constant and in rows $5-8$ by the value $\bar{s}_{t}$ that would give purchasing power parity (with 1973-1980 as the base period). We are unable to reject a random walk in several (limited) post-1976 sample periods. We argued in section II.1 that the theoretical case for a reversion to equilibrium rather than a random walk is much stronger in the case of the real exchange rate than it is for the nominal exchange rate. Rows 9-12 of Table 4a report tests of the tendency to regress toward $\vec{s}_{t}$ where the change in the exchange 
rate is adjusted for expected inflation rates. 50 If we wanted to apply the same rational expectations assumption to the price levels as to the nominal exchange rate, we would be back in section II.l's tests of changes in the real exchange rate. The results on our limited post-1976 sample periods are the same as in most tests of ex ante purchasing power parity on the floating rate period: we can find no statistically significant tendency to regress toward an equilibrium.

These findings are exactly what we would expect from our earlier conclusion that the speed of return to PPP may in fact be in the range of 15-25 percent a year, but that the floating rate period does not offer enough data to reject zero statistically. If we are sufficiently confident about both the gradual tendency to return to equilibrium in the 1onger run--based, for example, on the 115 years of U.S.-U.K. data-and the rational expectations assumption, we can infer that speculators must have stabilizing expectations. But it would be better to have more tangible evidence, since the 115 year autoregressions cover a number of different economic policy regimes.

Table $4 \mathrm{~b}$ uses the forward discount to measure expected depreciation in the same regression equations. Such regressions will only be valid in the unlikely case that the risk premfum is uncorrelated with the righthand-side variable (the current spot rate relative to its equilibrium). Not surprisingly, the results are poor. Even when the correction for expected inflation is applied, which makes the equation essentially a regression of the short-term real interest differential against the real exchange rate, the coefficient is statistically insignificant. Others have gotten better results on larger data sets. 


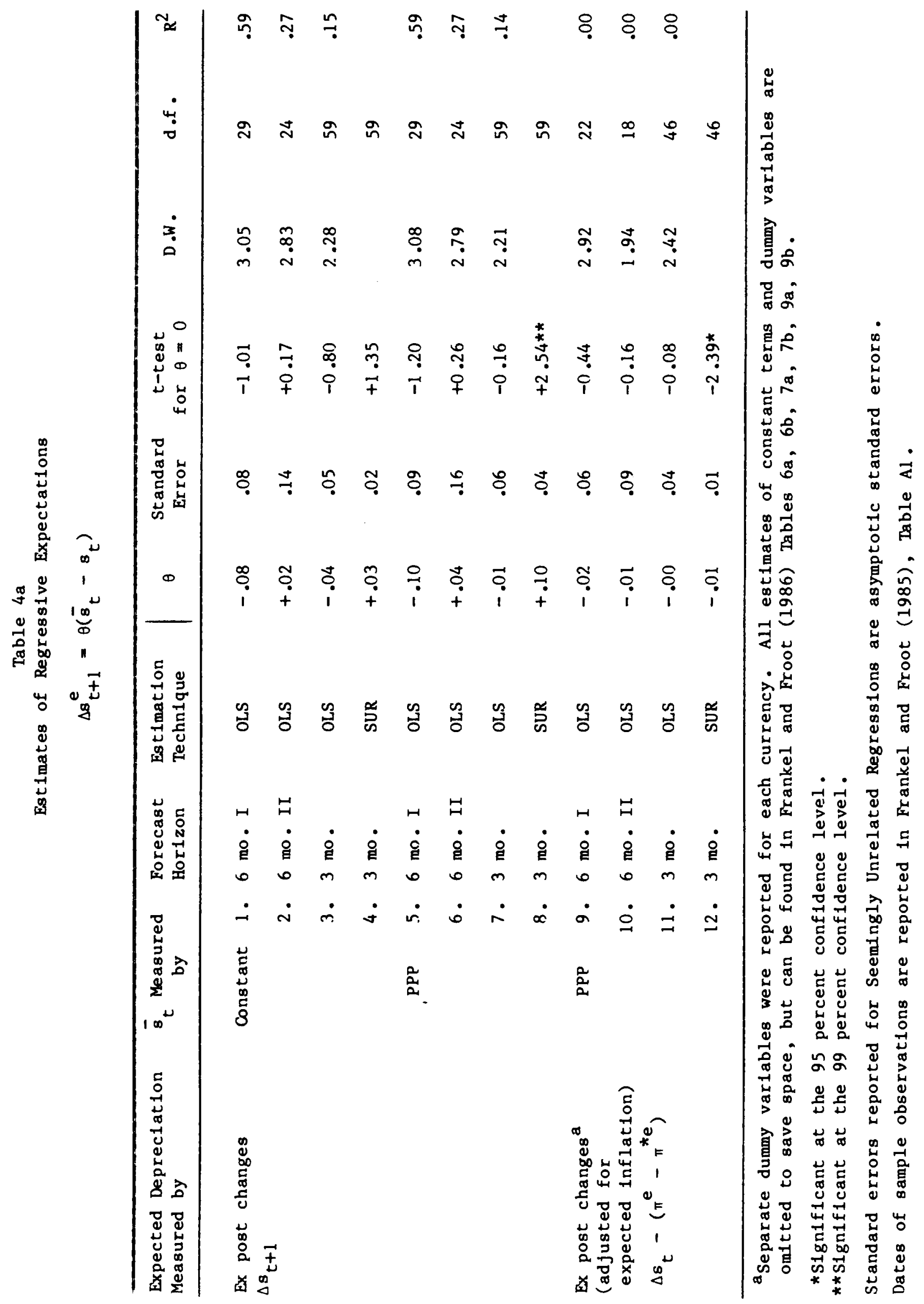




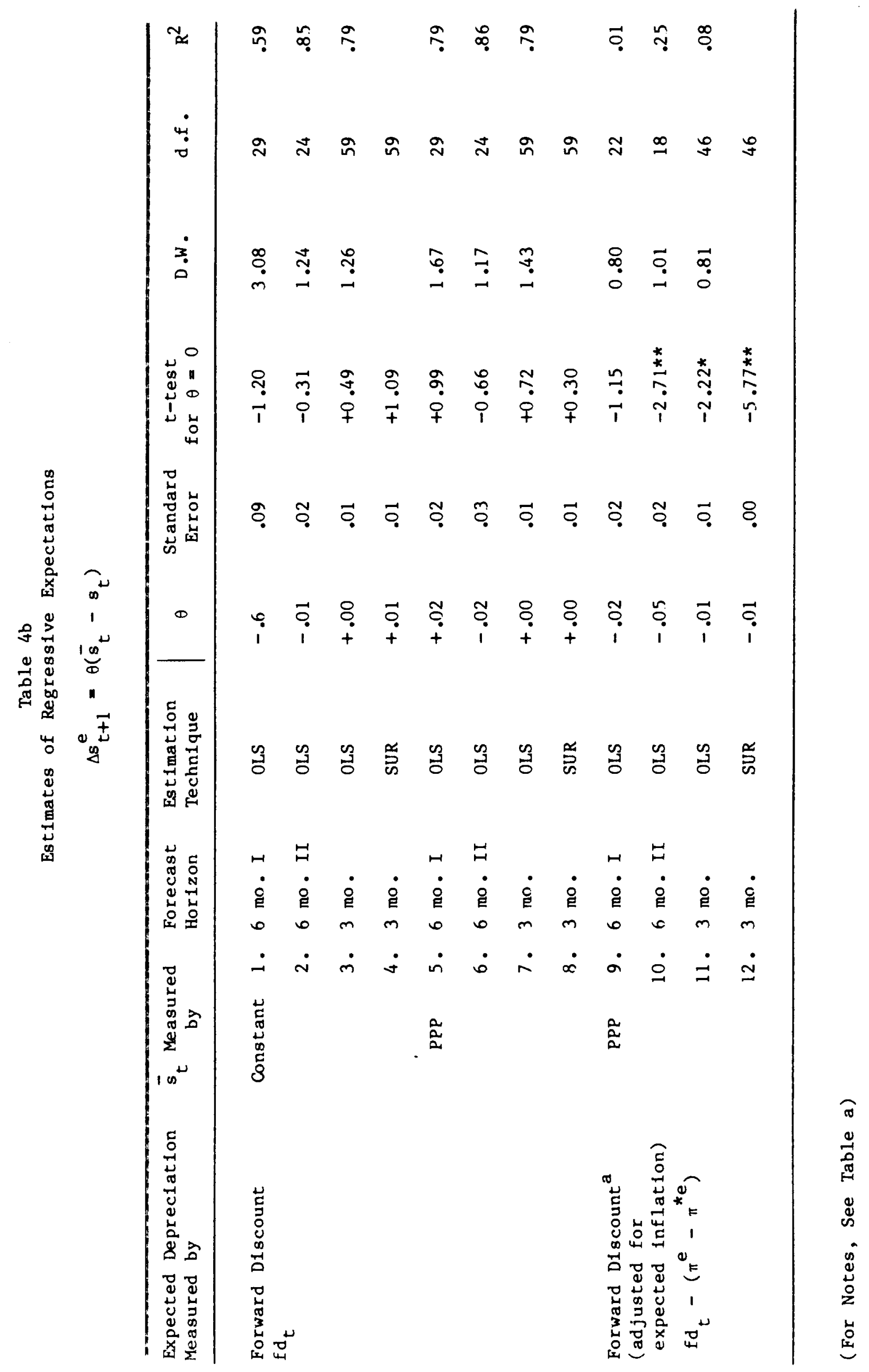




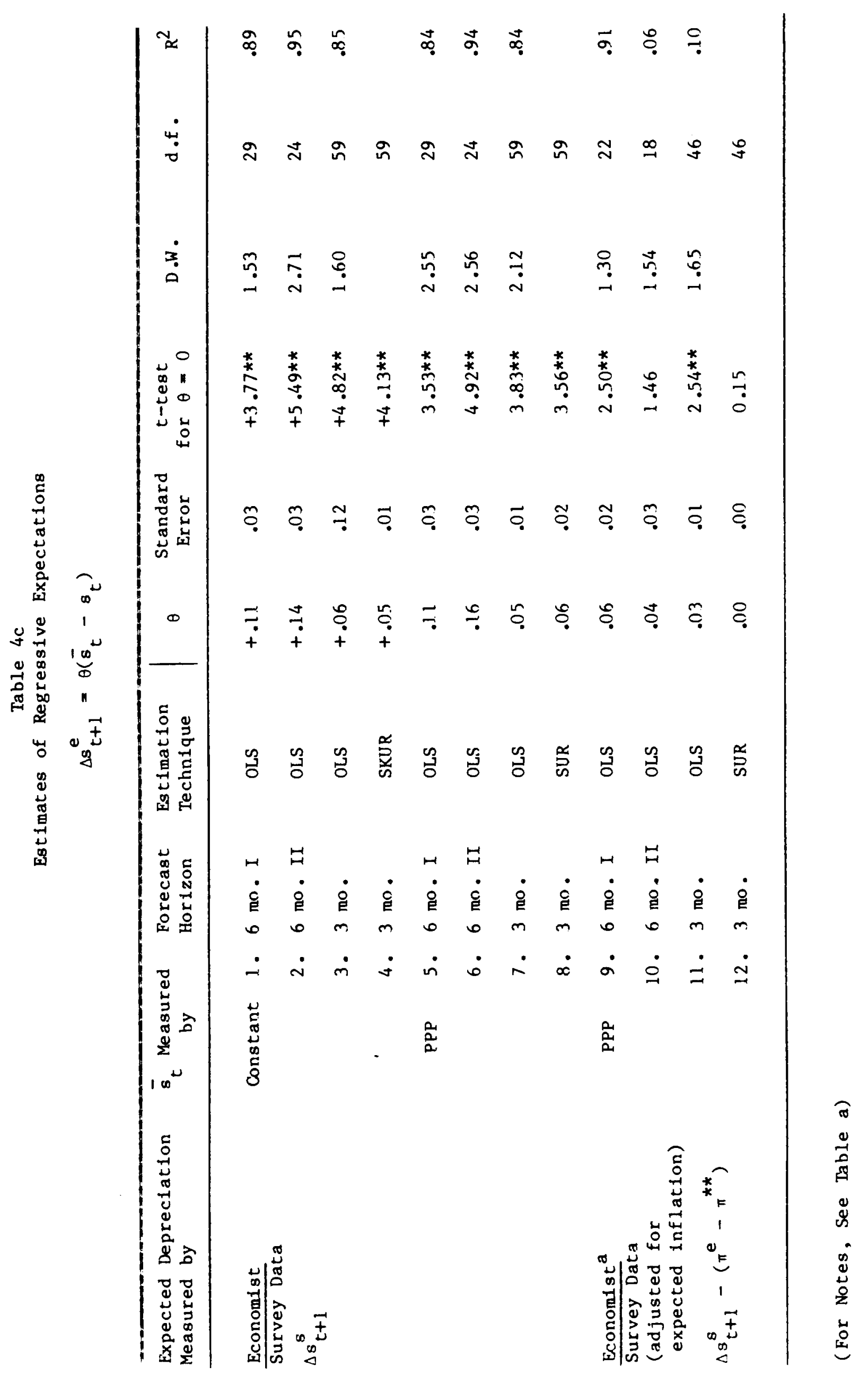


TABLE 4d

REGRESSIVE EXPECTATIONS

Independent variable: $\bar{s}(t)-s(t)$

$\bar{s}$ measured by PPP

SUR Regressions(1) of Survey Expected Depreciation:

$$
E(s(t+1))-s(t)=a+\theta(\vec{s}(t)-s(t))
$$

\begin{tabular}{|c|c|c|c|c|c|c|c|}
\hline Data Set & Dates & $\begin{array}{c}\text { Coefficien } \\
\hat{\theta}\end{array}$ & $t: \theta$ & $=0$ & $\mathrm{DW}(2)$ & DF & $\mathrm{R}^{2}$ \\
\hline MMS 1 Week & $10 / 84-2 / 86$ & $\begin{array}{l}-0.0283 \\
(0.0080)\end{array}$ & -3.53 & $\star \star \star$ & 2.10 & 219 & 0.58 \\
\hline MMS 2 Week & $1 / 83-10 / 84$ & $\begin{array}{l}-0.0299 \\
(0.0079)\end{array}$ & -3.78 & ** & 2.15 & 179 & 0.61 \\
\hline MMS 1 Month & $10 / 84-2 / 86$ & $\begin{array}{l}-0.0782 \\
(0.0134)\end{array}$ & -5.84 & $\star \star$ & 1.40 & 151 & 0.79 \\
\hline MMS 3 Month & $1 / 83-10 / 84$ & $\begin{array}{l}-0.0207 \\
(0.0146)\end{array}$ & -1.41 & & 1.55 & 179 & 0.18 \\
\hline Economist 3 Month & $6 / 81-12 / 85$ & $\begin{array}{c}0.0223 \\
(0.0126)\end{array}$ & 1.78 & * & 1.66 & 184 & 0.26 \\
\hline Amex 6 Month & $1 / 76-8 / 85$ & $\begin{array}{c}0.0315 \\
(0.0202)\end{array}$ & 1.56 & & 1.22 & 45 & 0.21 \\
\hline Economist 6 Month & $6 / 81-12 / 85$ & $\begin{array}{c}0.0600 \\
(0.0159)\end{array}$ & 3.77 & $\star \star$ & 1.32 & 184 & 0.61 \\
\hline Amex 12 Month & $1 / 76-8 / 85$ & $\begin{array}{c}0.1236 \\
(0.0276)\end{array}$ & 4.48 & $\star \star \star$ & 0.60 & 45 & 0.69 \\
\hline Economist 12 Month & $6 / 81-12 / 85$ & $\begin{array}{c}0.1750 \\
(0.0216)\end{array}$ & 8.10 & $\star \star *$ & 1.25 & 184 & 0.88 \\
\hline
\end{tabular}

(1) Amex 6 and 12 Month regressions use OLS due to the small number of degrees of freedom

(2) The DW statistic is the average of the equation by equation OLS DurbinWatson statistics for each data set.

* represents significance at the 10 percent level.

** represents significance at the 1 percent level.

$R^{2}$ corresponds to an $F$ test on all nonintercept parameters.

The above results are reported in Frankel and Froot (1985).

Constant terms for each currency were included in the regressions, but not reported above. 
Hooper (1985), Hutchison and Throop (1985), Golub et al (1985), Sachs (1985) and Feldstein (1986) report regressions with the two variables reversed, and find that the long-term real interest differential, in particular, is a significant factor explaining the real exchange rate. But when Meese and Rogoff (1986) examine real versions of the sticky price monetary model of section II.2, they find that real interest differentials cannot explain movements in real exchange rates significantly better than a random walk model. (The advantage of testing the sticky price monetary model in real terms is that one abstracts from instability in money demand parameters. Given the assumptions employed in their paper, monetary shocks have proportionate effects on the real exchange rate and real interest differential, and hence net out of the analysis.) In any case, the entire approach of using the interest differential or forward discount to measure expected depreciation will be viewed as suspect by those concerned by the risk premium.

What is sorely needed is an alternative to measuring expected depreciation either by ex post exchange rate changes or by the forward discount, one that does not require pre-judging either the unbiasedness of expectations or the existence of the risk premium. A good candidate for such a measure is offered by surveys of the exchange rate expectations of market participants. One such survey has been conducted every six weeks since 1981 by the Economist-affiliated Financial Report. The data are discussed and analyzed at length in Frankel and Froot $(1985,87)$ and Froot and Frankel (1986).

Table $4 c$ reports regressions of regressive expectations with expected depreciation measured by the Economist survey data, for the 
same samples of observations that were used in the preceding regressions of ex post changes and forward discounts..$^{51}$ Almost all the results show a highly significant expectation of regression toward equilibrium, at a rate of about 10 percent in the case of expectations at a six-month horizon, which is $\left(1-.9^{2}\right)=20$ percent per year. (The expected speed of adjustment per year is somewhat lower in the case of the three-month horizon.) This expected speed of adjustment to PPP is in the range of the actual speeds of adjustment estimated in Table 1, suggesting that the low power in the regressions of ex post changes in Table $4 a$ might alone have been responsible for the fallure to reject a random walk. 52 other tests reported in Frankel and Froot (1987), Dominguez (1986), and Froot and Frankel (1986), show that the prediction error made by the survey numbers is not in fact random. The tests constitute a rejection of rational expectations (jointly with the hypothesis of no regime changes or other peso problem) that is free from any concerns about the risk premium. Generally, the true spot process behaves more like a random walk than the survey respondents realize. In terms of the language attributed to Bilson (1981) in section II.3 above, there is excessive speculation: investors would do better to reduce their expectations of exchange rate changes toward zero. In terms of the specific regressive expectations model estimated in Table $4 \mathrm{c}$, survey respondents overestimate the speed of return to equilibrium. One might think that such a fallure of market efficiency would be evidence of the sort we are looking for, that "exchange markets are not working properly." But a tendency for speculators to expect the exchange rate to regress toward the equilibrium at a faster rate than is 
correct is stabilizing. An increase in the value of the currency, due in the context of equation (2) to an increase in the interest differential $1-1^{*}$ or the error term $u$ for example, will be damped because of the effect on expectations. We saw in equation (10) that the variability of the exchange rate in the Darnbusch overshooting model is inversely related to the value of $\theta$. A high $\theta$ means that, for any given positive interest differential, it takes less of an appreciation to generate the necessary expectations of future depreciation .53

One cannot work with the survey data on expectations without pondering the issue of heterogeneous expectations. Almost all of the exchange rate literature, theoretical as well as empirical, presupposes that market participants all share the same expectation. But the truth is that people disagree. Disagreement can explain the very high volume of trading in the spot and forward exchange markets. The Economist's Financial Report shows quite a range of variation in their survey responses; the high-low spread for the six-month expectations averages 15.2 percent. (The regressions reported in the tables here are based on the median response.)

The possibility of heterogeneous expectations introduces another possible source of variability into the exchange rate: the market in the aggregate may shift over time the weights it assigns to different forecasting mechanisms, for example the weight assigned to regressive versus bandwagon expectations in equation (5). The market may increase the weight it gives to one of these formulations if it has recently been forecasting better than the other. This could happen if portfolio managers update in a Bayesian way the weights they place on the forecasts of 
different models. Alternatively, it could happen when those investors who bet correctly gain wealth and receive more weight in the market in the next period. As the weight placed by the market on different expectations shifts, the aggregate demand for foreign currency and therefore the exchange rate will change over time. Even if no single forecaster holds destabilizing bandwagon expectations, any factor pushing up the value of the currency, such as an increase in $\left(i-i^{*}\right)$ or $u_{t}$, will produce a drawn-out appreciation as the weight placed on the optimistic forecasts gradually increases. Although none of the actors in such a model is satisfying the rational expectations assumption in the sense of knowing the complete process that is driving the exchange rate, neither is any of the actors behaving foolishly. Putting more weight on bandwagon expectations than on regressive expectations would have given the right answer in the case of the dollar from 1981 to February 1985, for example, but would have lost the investor a lot of money thereafter. In such a changing world it is difficult to see what variables it would be "rational" for the investors to grant more welght. We can offer some evidence for the idea that forecasters don't concur on a single stabilizing sort of expectations model as nicely as the estimates of regressive expectations in Table $4 c$ would suggest. Money Market Services, Inc., has conducted since 1983 a weekly survey of currency traders as to their forecasts at shorter-term horizons than the Economist survey. Estimates of regressive expectations on these two sets of survey data, together with a third conducted by the American Express Bank Review Irregularly between 1976 and 1985, are reported in Table 4d. The nine data sets are ordered by forecast horizon. The 
results are striking. The longer-term forecasts are strongly regressive: the Economist 12-month forecasts show that a 10 percent appreciation today generates the expectation of a 1.75 percent depreciation over the subsequent year. The shorter-term forecasts show precisely the reverse however: a 10 percent appreciation today generates the expectation of 0.78 percent further appreciation over the next month. This suggests the possibility that the forecasters who subscribe to bandwagon expectations ("chartists," or technical analysts, who use time series analysis to extrapolate past trends) tend to be traders with a shorter-term outlook, while those who subscribe to regressive expectations ("fundamentalists," who forecast a return to macroeconomic equilibrium) tend to be economists with a longer-term outlook. A small change in the weight that the market gives to two such different forecasts could have a big effect on the exchange rate, especially if asset demands are as sensitive to expected rates of return as was suggested by some of the subst1tutability arguments in section III. 54

\section{Conclusion}

The question, "are exchange rates excessively variable?", cannot be answered by comparing the variance of the actual exchange rate to the variance of a set of macroeconomic fundamentals. Overshooting theories, which are based on fundamentals and are consistent with market efficiency, allow exchange rate variability to exceed monetary variability by an indefinitely high multiple.

More damaging is the finding of regression tests that measurable fundamentals do not explain the exchange rate well, even contempo- 
raneously. The proposition that the exchange rate follows a random walk, in the sense that first differences cannot be explained by anything, may be unnecessarily nihilistic. There does appear to be some tendency for the exchange rate to return to equilibrium at longer horizons. Even the dollar came home to earth in 1985-86. But the error term is very large in the shorter-term (e.g. monthly) data that is available for most econometric studies.

It is tempting to argue that there must exist fundamentals of which market investors are aware but the econometrician is not. Such an argument might be supported by any evidence that the market could predict future exchange rates better than the mode1s; but there is no such evidence. Expectations measured by the forward exchange market (or by survey data) contain no useful information for predicting exchange rate changes. The very bad performance of the forward discount, either as a predictor of future changes in the forward exchange rate or as a contemporaneous determinant of the level of the exchange rate in equations such as (8), could in theory be attributed to an exchange risk premium. The framework of optimal portfolio diversification and conventional estimates of the degree of risk-aversion seem to imply that the risk premium does not vary enough to acquit the forward exchange market. A welcome recent line of research takes the source of variation to be changes in the conditional variance rather than changes in asset supplies. But this literature has yet to demonstrate that such variation in the conditional variance can explain the bias in the forward rate. We have seen that small changes in the variance, unless transitory, could produce large changes in the demand for assets and therefore 
in the exchange rate as opposed to the risk premium.. But unless "changes in the variation in the exchange rate" is considered an enlightening explanation of variation in the exchange rate, we are still mostly in the dark.

One need not explain all the fluctuations in the exchange rate to evaluate the scope for government policy. 55 Policy-makers could affect the foreign exchange market through three different channels. First, macroeconomic policy, for example interest rates and the mix between monetary and fiscal policy, has large effects (the poor regression reults not withstanding). We have not explored the resulting policymaking tradeoff between the exchange rate and other macroeconomic objectives in this paper. They are thoroughly discussed elsewhere, and the regression tests in any case suggest that the major determinants of the exchange rate, at least on a shorter-term basis, lie elsewhere. Second, Tobin (1978) and Dornbusch (1986) have argued that a tax on international borrowing or on other forelgn exchange transactions would reduce the extent to which investors could react to small changes in the attractiveness of different countries' assets, and would thereby reduce exchange rate volatility. As we noted in section $I .2$, this argument requires that expectations be destabilizing. If expectations are instead stabilizing, then a decrease in the degree of substitutability would increase exchange rate volatility rather than the reverse. On the other hand a Tobin tax on foreign exchange transactions should work to discourage short-term trading more than long-term trading, since the given tax is a higher percentage of the return for shorter term transactions. If our survey data findings are correct and 
short-term expectations (less than 3 months) are destabilizing but longterm expectations (greater than 3 months) stabilizing, then a Tobin tax might reduce volatility after all.

Third, others argue that central banks should intervene in foreign exchange markets to dampen fluctuations. Foreign exchange intervention of course is generally thought to affect the exchange rate to the extent it changes the relevant macroeconomlc fundamentals, particularly nonsterilized intervention that allows the change in reserves to change the money supply. But effects via current macroeconomic fundamentals should be subsumed in the first category above. If foreign exchange intervention is to have an independent effect, particularly if sterilized intervention is to have a substantial effect, it will be via investor expectations of future exchange rate changes. The strongest case for steps toward reform of the floating rate system would be if one could demonstrate that expectations are destabilizing, producing bandwagons in the exchange rate, and that a change in government policy might alter these expectations even without altering asset supplies, for example, by bursting a speculative bubble. The announcement on September 22, 1985, that the G-5 had decided at the Plaza Hotel to work to bring the dollar down caused an instant 5 percent depreciation of the dollar. While the fall in demand for dollars could be explained as a rational re-evaluation of the future expansionariness of U.S. monetary policy, it might also be explained as the bursting of a bubble. Our theories of rational speculative bubbles have virtually nothing to say about what causes the price to jump from one bubble path to another. But this is precisely the sort of effect for which many 
proponents of a more activist policy are looking. Proponents of a target zone argue that the stabilizing effect would be even greater if the government announced a change in policy regime, rather than a onetime initiative of the sort that took place at the Plaza.

The key question, then, seems to be the behavior of investor expectations. In particular, much hinges on whether expectations when left to themselves are destabilizing. The question whether the true spot process matches up with the expected one, $1 . e .$, whether expectations are rational, is not as directly relevant. The evidence appears to be that expectations are stabilizing, at least at horizons greater than three months. The survey data at a six month horizon reported in Table 4c, for example, show that a 10 percent appreciation today generates an expected future depreciation of about 1 percent, or 2 percent at a per annum rate. If speculators are investing on the basis of these expectations, then they are acting to stabilize the exchange rate. A Tobin tax to discourage speculation might then raise variability .

Survey data at short horizons show quite different results however. It seems likely that expectations are in fact heterogeneous. One consequence is that "the" expectation can't be rational if investors do not agree on a single expectation. A second implication follows from the high degree of substitutability (for an average value of the variance) that we found in section III: small changes in the weights that the market assigns to competing exchange rate forecasts will produce large changes in portfolio preferences and thus large changes in the exchange rate. This source of exchange rate variability could be 
classed as a speculative bubble in the sense that it arises from selfconfirming changes in expectations rather than from fundamentals, though it is not the rational speculative bubble that has been extensively studied recently.

As Krugman (1985) has argued, when the market has temporarily "lost its moorings," it is possible that a more activist policy can restore the anchor to expectations. Investors might be persuaded to expect more of a tendency to return to equilibrium. But central bank governors and finance ministers of major countries will only be able to affect expectations if they have credibility. They did not have credibility in 1973. In this sense the breakdown of the fixed exchange rate system was inevitable. They have more credibility today; this much is clear from the market's sensitivity to every utterance of the Treasury Secretary and the Chairman of the Federal Reserve, and their Japanese and German counterparts. Whether this credibility would still be there if policy-makers tried to exploit it more systematically with a reform of the world monetary system is another question, especially if one allows for the usual politicization of any process of choosing targets for an economic price that affects people's livelihoods. 


\section{Appendix 1}

Consider an ARIMA $(0,1,1)$ model for $\Omega_{t} ; \Omega_{t}=\Omega_{t-1}+\delta_{t}-\alpha \delta_{t-1}$ with $0<\alpha<1$. The linearized effect on $s_{t}$ of a shock $\delta_{t}$ to $\Omega_{t}$ can be obtained from the following expression.

$$
\begin{aligned}
\frac{d s_{t}}{d \delta_{t}} & =\left(\frac{1}{x_{t}}+\frac{1}{1-x_{t}}\right)\left[\frac{r \rho_{t}}{\rho \Omega_{t}^{2}} \frac{d \Omega_{t}}{d \delta_{t}}-\frac{1}{\rho \Omega_{t}}\left(\frac{d s_{t}}{d \delta_{t}}-\frac{d s_{t+1}^{e}}{d \delta_{t}}\right)\right] \\
& =\phi_{t}\left[\frac{r p_{t}}{\Omega_{t}}+\frac{d s_{t+1}^{e}}{d \delta_{t}}\right], \text { where } d_{t}=\left(1+\rho \Omega_{t} /\left(\frac{1}{x_{t}}+\frac{1}{1-x_{t}}\right)\right)^{-1} \text {, a number }
\end{aligned}
$$

slightly less than one. Now assuming the initial position represented an equilibrium we can take $\Omega_{t}, x_{t}$ and $\mathrm{rp}_{t}$ to be constant so that

$$
\begin{aligned}
\frac{d s_{t+1}^{e}}{d \delta_{t}} & =\left(\frac{1}{x_{t+1}}+\frac{1}{1-x_{t+1}}\right)\left[\frac{r \rho_{t+1}}{\rho \Omega_{t+1}}(1-\alpha)-\frac{1}{\rho \Omega_{t+1}}\left(\frac{d s_{t+1}^{e}}{\alpha \delta_{t}}-\frac{d s_{t+2}^{e}}{d \delta_{t}}\right)\right] \\
& =\phi_{t}\left[\frac{r \rho_{t}}{\Omega_{t}}(1-\alpha)+\frac{d s_{t+2}^{e}}{d \delta_{t}}\right] \text { Lfkewise, } \frac{d s_{t+2}^{e}}{d \delta_{t}}=\phi_{t}\left[\frac{r \rho_{t}}{\Omega_{t}}(1-\alpha)+\frac{d s_{t+3}^{e}}{d \delta_{t}}\right] .
\end{aligned}
$$

Combining these results we obtain

$$
\begin{aligned}
\frac{d s_{t}}{d \delta_{t}} & =\phi_{t} \frac{r \rho_{t}}{\Omega_{t}}\left[1+(1-\alpha) \phi_{t}+(1-\alpha) \phi_{t}^{2}+\ldots\right] \\
& =\phi_{t} \frac{r \rho_{t}}{\Omega_{t}}\left[1+(1-\alpha)\left(\frac{1}{1-\phi_{t}}-1\right)\right]
\end{aligned}
$$

Using our benchmark values for $x_{t}, r \rho_{t}, \Omega_{t}$ and $\rho, \phi_{t}=(1.005)^{-1}$. If we can also assume that $\alpha=.9$ as in equation (21) for $\sqrt{\Omega}_{t}$, then $\frac{d s_{t}}{d \delta_{t}}=-63.3$. Therefore, the 1inearized effect on the spot rate of a .01 change in $\Omega_{t}$ is an aproximately $63 \%$ appreciation of the less risky currency. 
For the case where $\Omega_{t}$ follows an AR(1) process, $\Omega_{t}=\alpha \Omega_{t-1}+\delta_{t}$ with $|\alpha|<1, \frac{d s_{t+1}^{e}}{d \delta_{t}}=\phi_{t}\left[\frac{r \rho_{t}}{\Omega_{t}} \alpha+\frac{d s_{t+2}^{e}}{d \delta_{t}}\right]$. Therefore, $\frac{d s_{t}}{d \delta_{t}}=\phi_{t} \frac{r \rho_{t}}{\Omega_{t}}\left[1+\alpha \phi_{t}+\alpha^{2} \phi_{t}^{2}+\ldots\right]=\phi_{t} \frac{r \rho_{t}}{\Omega_{t}}\left(\frac{1}{1-\alpha \phi_{t}}\right)$. If $a=.9$, then $\frac{d s_{t}}{d \delta_{t}} \approx-30 \%$ for a .01 change in $\Omega_{t} \quad$ assuming our benchmark parameter values. 


\section{Footnotes}

1Friedman (1950)

${ }^{2}$ See, for example, Williamson (1985).

${ }^{3}$ Among many possible citations are Isard (1977), Krugman (1978), Frenkel (1981), Engel and Frankel (1984), and Hardouvelis (1987). Variation in the real exchange rate is documented in section II.1.

${ }^{4}$ In Section III.l below, we will see that this linear form is the correct one for an asset demand function under the assumption of meanvariance optimization by investors.

${ }^{5}$ For example, Meese and Rogoff $(1983 a, b)$.

${ }^{6}$ Within the framework of equations (2) and (4), we can easily insert a role for the (cumulated) current account by defining the asset demand of residents of country 1 to be $x_{1}=A_{1}-B(r p)$, and aggregating: (3') $x=\sum w_{1} A_{1}-B(r p)$, where $w_{1}$ is the share of world wealth held by residents of country 1 , which includes their cumulated claims on foreigners.

${ }^{7}$ See, for example, Dooley and Shafer (1983).

${ }^{8}$ Frankel and Froot (1986) show the equivalence. Note that in the monetary model, $\mathrm{dL} / \mathrm{d}(\mathrm{rp})=\infty$.

${ }^{9}$ For example, Meese and Rogoff $(1983 a, b)$.

10 The probability of collapse may rise as $s$ gets farther from equilibrium. If not, the ratio $g /(1-\theta)$ would have to be greater than 
one, unless the expected rate of depreciation (equal to the interest differential under uncovered interest parity) is to be declining over time as the bubble proceeds.

${ }^{11}$ For example, Council of Economic Advisers (1984).

12 Edison, Miller and Williamson (1986) is an attempt to show how a target zone would actually work in a macroeconomlc model and Mckibbin and Sachs (1986) does the same for a variety of regimes. Also beyond the scope of this paper is the question whether it is even a feasible option for government intervention in foreign exchange markets to stabilize the exchange rate without changing monetary and fiscal policy, as are related questions of International policy coordination. However the magnitude of our substitutability parameter $B$ is relevant to the question of the effectiveness of sterilized intervention, as elaborated In Frankel (1986a).

${ }^{13}$ Poole (1967), Giddy and Dufey (1975), Mussa (1979) and Meese and Rogoff (1983a,b), among others.

${ }^{14}$ We consider time-varying variances more in section III.2.

${ }^{15}$ The following discussion draws on Frankel (1986b).

${ }^{16}$ Roll (1979), Adler and Lehman (1983), Pippenger (1986).

17 Cumby and Obstfeld (1984, p. 146) used a Q-statistic to test for higher order serial correlation in monthly real exchange rate changes and found none. However, they also found that expected 
inflation differentials are unrelated to expected exchange rate changes, rejecting the random walk characterization of the real exchange rate. Huizinga (1986) is also able to reject the random walk.

18 Hakkio's unrestricted process allows for a unit root. Simflarly the last line in Table 1 allows for the possibility of a trend. From a macroeconomic viewpoint, rather than a statistical one, one might consider the important question to be whether most changes in the real exchange rate die out over time, rather than whether there are sometimes also permanent changes in the real exchange rate, for example, when the price of oil goes up.

${ }^{19}$ Frenkel (1976), Mussa (1976) and Bilson (1978).

${ }^{20}$ This is the case where $B$ in equation (3) is infinite.

21 This proportionality is tested directly in Part IV below.

22 Dornbusch (1976), Frankel (1979).

${ }^{23}$ Branson (1977), Kour1 (1976), Girton and Henderson (1977).

${ }^{24}$ Frankel (1984), Hooper and Morton (1982).

${ }^{25}$ Overshooting can occur also in the portfolio-balance model, where it can be viewed as the consequence of a finite rate of adjustment in the stock of claims on foreigners, just as in the monetary model overshooting can be viewed as the consequence of a finite rate of adjustment in the general price level. 
${ }^{26}$ In Dornbusch, $\frac{1}{\lambda \theta}$ represents the amount of overshooting. For elaboration, see Frankel (1983, p. 42).

27 Frankel (1979). The sample went up to February 1978 .

28 For example, Meese and Rogoff (1983a), Frankel (1984), and Backus(1984). Somanath (1986) reports updated fit statistics for the above-mentioned models both insample (1975-1982) and out of sample (1983). Schinasi and Swamy (1986) use a method that allows coefficients to change over time. The two more recent papers claim relatively good results with a lagged endogenous variable.

${ }^{29}$ The rate-of-return term $(1-i *)$ in equation (8), seems for some reason to generate more econometrician anxiety over endogeneity problems when $1 t$ is expressed as expected depreciation, $\Delta s^{e}$ in equation (9), even though it is the same variable when covered interest parity holds.

30 Meese and Rogoff (1983b) try a grid of parameter values. Outof-sample performance, while better than a random walk at horizons exceeding 18 months, is never good.

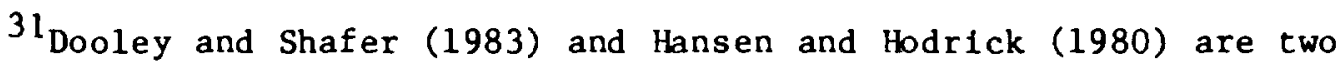
of the tests that take the lagged prediction errors to be the available information.

${ }^{32}$ Studies regressing against the forward discount include Tryon (1979), Levich (1980), Btlson (1981), Longworth (1981), Longworth, Boothe and Cinton (1983), Fama (1984) and Huang (1984). Cumby and 
Obstfeld (1984) and Obstfeld (1986) regressed against the Eurocurrency Interest differential and again found that for most exchange rates the coefficlent was significantly less than 1.0 and even less than zero. (One would expect the same finding as in the forward discount tests, given that the interest differential is equal to the forward discount by covered interest parity.) These findings are also consistent with those of Meese and Rogoff (1983a) that the random walk predicts, not only better than other models, but better than the forward market as well.

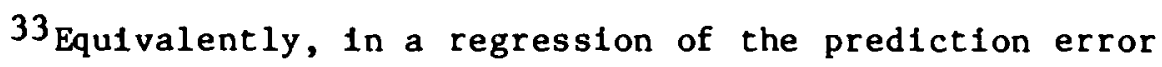
$\Delta s_{t+l}-f_{t}$ against $f d_{t}$, the coefficient under the null hypothesis should be zero.

${ }^{34}$ E.g. Frenkel (1978) and Frankel (1980).

${ }^{35}$ See Meese (1987) for a more r1gorous argument.

${ }^{36}$ An exception is the unlikely case where, even though investors are risk-averse, exchange rates are like the outcome of a bet on a football game in that they are completely uncorrelated with other rates of return (on all "outside" assets), so that exchange risk is completely diversifiable.

${ }^{37}$ This statement assumes a Cobb-Douglas price Index with weight $\alpha$ on foreign goods. The constant term a in equation (11) can then be interpreted as the (conditional) variance of the exchange rate times $(a-1 / 2)$, which is a quite small number.

${ }^{38}$ Frankel (1980), Krasker (1980), or Rogoff (1979). 
${ }^{39}$ Recall that the tests of forward rate unbiasedness in the preceding section are also joint tests of rational expectations and no risk premium.

${ }^{40}$ If $u$ is known to be correlated with the monetary fundamentals but an appropriate instrumental variable is available, then equation (13) can still be estimated by the appropriate techniques, the same as the standard regression equation (8). Casella (1985), for example, allows for endogeneity of the money supply in her bubbles test of the German hyperinflation.

${ }^{41}$ One could presumably relax the assumption of no risk premium by specifying a portfolio-balance model, in place of (8), with bond supplies appearing on the righthand-side. Assumption (b) would then be the less-stringent condition that expected depreciation $\Delta s_{t}^{e}$ is an unbiased predictor in the sample (requiring rational expectations and no peso problem or regime changes). Woo (1984) has attempted this sort of bubbles test.

42 Fama (1984), Hodrick and Srivastava (1986) and Sweeney (1986) provide evidence of $\hat{b}<0$ on different data sets. Note that $\operatorname{cov}\left[\left(f_{t}-s_{t}\right),\left(s_{t+1}-f_{t}\right)\right]=\operatorname{cov}\left[\left(f_{t}-s_{t}\right),\left(s_{t+1}-s_{t}\right)-\left(f_{t}-s_{t}\right)\right]$ $=-\operatorname{var}\left(f_{t}-s_{t}\right)+\operatorname{cov}\left[\left(f_{t}-s_{t}\right),\left(s_{t+1}-s_{t}\right)\right]$. The sum of the last two terms is less than zero whenever $\hat{b}<0$.

${ }^{43}$ See Frankel (1982), Rogoff (1984), Dooley and Isard (1982) among others. 
${ }^{44}$ If investors are assumed to calculate their portfolios once a year, the numbers are slightly different. The annual variance in returns is observed to be about .01 . Then an increase in the supply of foreign assets equal to 1 percent of the portfolio of 2.0 basis points.

${ }^{45}$ Frankel (1982, p. 260) describes this assumption as one made for convenience, to focus on variation in asset supplies and the risk premium, with variation in the variances and covariances considered a priority for future research.

${ }^{46}$ This model marginally outperforms (i) an autoregressive model with lag length estimated, (ii) the sample mean or median, and (1ii) a random walk model, on the basis of out-of-sample fit.

${ }^{47}$ For simplicity we are leaving out the effect of a change in the return variance on the minimum variance portfolio A via the convexity term .

${ }^{48}$ Suppose $\Omega_{t}=\Omega_{0}+\delta_{t}$, where $\delta_{t}$ is now a purely transitory disturbance to $\Omega_{t}$. The effect of $\delta_{t}$ on the exchange rate will be considerably smaller than that implied by (22). Besides the direct effect on $\Omega_{t}$ from (22) we must recognize that the spot rate in the subsequent period will return to its previous level, so that the risk premium will rise by the full amount of the increase in $s_{t}$. Taking account of this second offsetting term we get:

$$
\begin{gathered}
\frac{d s_{t}}{d \delta_{t}}=\left(\frac{1}{x_{t}}+\frac{1}{1-x_{t}}\right)\left[\frac{r \rho_{t}}{\rho \Omega_{t}^{2}}-\left(\frac{1}{\rho \Omega_{t}}\right) \frac{d s_{t}}{d \delta_{t}}\right] \\
+\frac{d s_{t}}{d \delta_{t}} \approx \frac{r p_{t}}{\Omega_{t}}
\end{gathered}
$$


Note that the effect on expectations is much more important than the portfolio valuation effect, due to the high degree of substitutability. Again, if the Initial risk premium is close to zero, the effect on a change in the return variance is close to zero. But if the initial risk premium is .03 and we consider a transitory change in $\Omega_{t}$ from .01 to .02 , the change in the spot rate will be roughly $-(.03 / .01)(.01)=$ -.03 , or a 3 percent appreciation of the less risky currency.

${ }^{49}$ Note that the mean-variance model ( $\left.3^{\prime}\right)$ used to derive (22) is less applicable when $\Omega_{t}$ varies over time.

${ }^{50}$ The expected inflation rates used here are three-year forecasts by DRI .

${ }^{51}$ Indeed, the samples were dictated by the availability of the survey data.

52 It is noteworthy that the survey data regressions are valid even if the survey responses measure true expectations with error, so long as the measurement error is random. The standard error of the regression (and statistically significant coefficient estimates) imply that the magnitude of the measurement error is small, relative, for example, to the magnitude of the expectational errors introduced when ex post exchange rate changes are used as the lefthand-side vartable.

53 If we ask what happens when the true speed of regression to PPP is held constant but investors have a higher expected speed of regression $\theta$, it turns out that the effect is still to reduce variability. The effect on the conditional variance is shown in Frankel (1983). 
${ }^{54}$ For further elaboration on how such a model can work, see Frankel and Froot (1986).

${ }^{55}$ Dornbusch (1986) points out that someone who believes that exchange markets are not efficient need not necessarily believe that the government could do better, any more than someone who, like Tobin (1978), belleves that the markets are efficient need necessarily belleve in laissez-faire. 


\section{References}

Adler, Michael and Bruce Lehman. 1983. "Deviations from Purchasing Power Parity in the Long Run." Journal of Finance 39, 5

(December): $1471-1487$.

Backus, David. 1984. "Empirical Models of the Exchange Rate: Separating the Wheat from the Chaff." Canadian Journal of Economics 17: 824-6.

Bilson, John. 1978. "Rational Expectations and the Exchange Rate." In The Economics of Exchange Rates: Selected Readings, edited by Jacob Frenkel and Harry Johnson. (Reading: Addison-Wesley).

B1lson, John. 1981. "The Speculative Efficiency Hypothesis." Journal of Business 54 (July): 433-51.

Blanchard, Olivier and Mark Watson. 1982. "Bubbles, Rational Expectations and Financial Markets." NBER Working Paper, No. 945.

Bollerslev, T.; Engle, R.; and J. Wooldridge. 1985. "A Capital Asset Pricing Model with Time Varying Covariances." University of California, San Diego mimeo.

Boothe, P.; Clinton, K.; Cote, A .; and D. Longworth. 1985 . "International Asset Substitutability: Theory and Evidence for Canada." Bank of Canada.

Branson, William. 1977. "Asset Markets and Relative Prices in Exchange Rate Determination." IIES Seminar, Paper No. 66.

Casella, Alessandra. 1985. "A New Test for Price Level Bubbles." M.I.T. mimeo.

Council of Economic Advisers. 1984. "The United States in the World Economy." Chapter 2 of Economic Report of the President.

Cumby, Robert. 1986. "Is 1t Risk? Explaining Deviations From Uncovered Interest Parity." New York University mimeo.

Cumby, Robert; Huizinga, John; and Maurice Obstfeld. 1983. "Two-Step Two-Stage Least Squares in Models with Rational Expectations ." Journal of Econometrics 21: 333-55.

Cumby, Robert and Maurice Obstfeld. 1984. "International Interest Rate and Price Level Linkages Under Flexible Exchange Rates: A Review of Recent Evidence:" In Exchange Rate Theory and Practice, edited by J. Bilson and R. Marston. (Chicago: University of (hicago Press.) 
Darby, Michael. 1981. "Does Purchasing Power Parity Work?" Proceedings of the Fifth West Coast Academic/Federal Reserve Economic Research Seminar. Federal Reserve Bank of San Francisco.

Dickey, David and Wayne Fuller. 1979. "Distribution of the Estimators for Autoregressive THme Series with a Unit Root." Journal of American Statistical Association 74 (June) : 427-31.

Domlnguez, Kathryn. 1986. "Expectations Formation in the Foreign Exchange Market: New Evidence from Suvey Data." Economic Letters.

Domowitz, I. and C. Hakkio. 1985. "Conditional Variance and the Risk Premlum in the Foreign Exchange Market." Journal of International Economics 12: 257-276.

Dooley, Michael and Peter Isard. 1982. "A Portfollo Balance RationalExpectations Model of the Dollar-Mark Exchange Rate." Journal of International Economics 12: 257-76.

Dooley, Michael and Jeffrey Shafer. 1983. "Analysis of Short-Run Exchange Rate Behavior: March 1973 to November 1981." In Exchange Rate and Trade Instability: Causes, Consequences, and Remedies, edited by D. Bigman and T. Taya. (Washington, D.C.: International Monetary Fund).

Dornbusch, Rudiger. 1976. "Expectations and Exchange Rate Dynamics." Journal of Political Economy 84 (December): 1161-74.

- 1982. "Equilibrium and Disequilibrium Exchange Rates ." Zeitschrift fur Wirtschafts-und Sozialwissenshaften 102 , $6: \quad 573-599$.

- 1986. "Flexible Exchange Rates and Excess Capital Mobility." Brookings Papers on Economic Activity 1: 209-26.

Edison, Hal1; Miller, Marcus; and John Williamson. 1986. "On Evaluating and Extending the Target Zone Proposal." Institute for International Economics, Washington, D.C. Journal of Policy Modeling (Forthcoming).

Edchengreen, Barry. 1981. "Did Speculation Destabilize the French Franc in the 1920s?" Explorations in Economic History 19 (January) : 71-100.

Engel, Charles. 1984. "Testing for the Absence of Expected Real Profit Opportunities in the Foreign Exchange Market." Journal of International Economics 17: 299-308. 
Froot, Kenneth and Jeffrey Frankel. 1986. "Interpreting Tests of Forward Discount Bias Using Survey Data on Exchange Rate Expectations." NBER Working Paper, No. 1963 (June).

Fuller, Wayne. 1976. Introduction to Statistical Time Series. (New York: Wiley).

Geweke, J. and E. Feige, 1979. "Some Joint Tests of the Efficiency of the Markets for Forward Forelgn Exchange." Review of Economics and Statistics 61: 334-341.

Giddy, I, and G. Dufey. 1975. "The Random Behavior of Flexible Exchange Rates." Journal of International Business Studies 6: $1-32$.

Giovannini, A. and P. Jorion. 1987a. "Interest Rates and Risk Premia in the Stock Market and in the Foreign Exchange Market." Journal of International Money and Flnance (March).

- 1987b. "Foreign Exchange Risk Premla Volatility Once Again." Columbia University mimeo.

Girton, Lance and Dale Henderson. 1977. "Central Bank Operations in Foreign and Domestic Assets under Flxed and Flexible Exchange Rates." In The Effects of Exchange Rate Adjustments, edited by P. Clark, D. Logue, and R. Sweeney: 151-79. (Washington: U.S. Government Printing of fice).

Golub, Stephen, et al. 1985. "Exchange Rates and Real Long-Term Interest-Rate Differentials: Evidence for Eighteen OECD Countries." Economics and Statistics Department Working Papers, Organization for Economic Cooperation and Development, Paris.

Hakkio, Craig. 1984. "A Re-examination of Purchasing Power Parity: A Multi-Country and Multi-Period Study." Journal of International Economics 17 (November): 265-78.

- 1986. "Does the Exchange Rate Follow a Random Walk? A Monte Carlo Study of Four Tests for a Random Walk." Journal of International Economics (June): 221-230.

Hamliton, James and Charles Whiteman. 1986. "The Observable Implications of Self-Fulfilling Expectations. Journal of Monetary Economics.

Hansen, L. 1982. "Large Sample Properties of Generalized Method of Moments Estimators :" Econometrica.

Hansen, L. and R. Hodrick. 1980. "Forward Exchange Rates as Optimal Predictors of Future Spot Rates: An Econometric Analysis." Journal of Political Economy 88: 828-53. 
- 1984. "Tests of Monetary and Portfolio-Balance Models of Exchange Rate Determination." In Exchange Rate Theory and Practice, edited by J. Bllson and R. Marston. (Chicago: University of Chicago Press.)

- 1985. "The Dazzling Dollar." Brookings Papers on Economic Activity 1: 199-217.

- 1986a. "The Implications of Mean-Variance

Optimization for Four Questions in International

Macroeconomics." Journal of International Money and Finance (Supplement): S53-75.

- 1986b. "International Capital Mobility and Crowding Out in the U.S. Economy: Imperfect Integration of Financial Markets or of Goods Markets." In How Open is the U.S. Economy?, edited by $R$. Hafer. (Lexington: Lexington Books).

Frankel, Jeffrey and Kenneth Froot. 1985. "Us1ng Survey Data to Test Some Standard Propositions Regarding Exchange Rate Expectations." NBER Working Paper No. 1672 (August). Abridged in American Economic Review (Forthcoming; March 1987).

- 1986. "Explaining the Demand for Dollars:

International Rates of Return and the Expectations of Chartists and Fundamentalists." Economics Working Paper, No. 8603, U.C. Berkeley (June). Abridged in Economic Record (Forthcoming).

Frankel, Jeffrey and James Stock. 1987. "Regression vs. Volatility Tests of Foreign Exchange Markets." Journal of International Money and F1nance 6: 49-56.

Frenke1, Jacob. 1976. "A Monetary Approach to the Exchange Rate: Doctrinal Aspects and Empirical Evidence," Scandinavian Journal of Economics 78: 200-24.

- 1981. "The Collapse of Purchasing Power Parity During the 1970's." European Economic Review 16: 145-65.

Frenkel, Jacob and A. Razin. 1980. "Stochastic Prices and Tests of Efficiency of Foreign Exchange Markets." Economic Letters 6: $165-70$.

Friedman, Milton. 1953. "The Case for Flexible Exchange Rates." In Essays in Positive Economics, edited by Milton Friedman. (Chicago: University of Chicago Press): 157-203.

Froot, Kenneth. 1987. "Tests of Excessive Variability in Asset Markets ." Sloan School, M.I.T (April). 
Hutchinson, Michael and Adrian Throop. 1985. "U.S. Budget Deficits and the Real Value of the Dollar." Economic Review 4, Federal Reserve Bank of San Francisco (Fal1): 26-43.

Isard, Peter. 1977. "How Far Can We Push 'The Law of One Price'?" American Economic Review.

Kohlhagen, Steven. 1979. "On the Identification of Destabilizing Speculation." Journal of International Economics 9 (August): $321-40$.

Kour1, Penti. 1977. "International Investment and Interest Rate Linkages Under Flexible Exchange Rates." In The Political Economy of Monetary Reform, edited by R. Aliber. (Macmillan).

Krasker, William. 1980. "The 'Peso Problem' in Testing the Efficiency of Forward Exchange Markets." Journal of Monetary Economics 6: 269-76.

Krugman, Paul. 1978. "Purchasing Power Parity and Exchange Rates: Another Look at the Evidence." Journal of International Economics 8: 397-407.

- 1985. "Is the Strong Dollar Sustainable?" In The U.S. Dollar--Recent Developments, Outlook, and Policy Options, (Kansas CIty: Federal Reserve Bank).

Levich, Rtchard. 1979. "On the Efficiency of Markets for Foreign Exchange." In International Economic Policy: Theory and Evidence, edited by R. Dornbusch and J. Frenkel. (Johns Hopkins).

Longworth, David. 1981. "Testing the Efficiency of the Canadian-U.S. Exchange Market Under the Assumption of No Risk Premium." Journal of Finance 36 (March) : 43-49.

Longworth, David; Boothe, Paul; and Kenneth Clinton. 1983. "A Study of the Efficiency of Foreign Exchange Markets." Ot towa: Bank of Canada .

Lucas, Robert. 1982. "Interest Rates and aurrency Prices in a TwoCountry World." Journal of Monetary Economics 12, 55-93.

Lyons, Rfchard. 1986. "Tests of the Foreign Exchange RAsk Premfum Using the Expected Second Moments Implied by Options Pricing." M.I.T. mimeo.

McCallum, Bennett. 1976. "Rational Expectations and the Natural Rate Hypothesis: Some Consistent Estimates :" Econometrica 44: 43-52. 
- 1983. "Rlsk Averse Speculation in the Forward Foreign

Exchange Market: An Econometric Analysis of Linear Models ." In

Exchange Rates and International Macroeconomics, edited by $\mathrm{J}$.

Frenkel. (Chicago: University of Chicago Press).

Hansen, L. and T. Sargent. 1980. "Formulating and Estimating Dynamic

Linear Rational Expectations Models." Journal of Economic

Dynamics and Control.

Hardouvelis, Gikas. 1987. "Reserves Announcements and Interest Rates: Does Monetary Policy Matter?" Journal of Finance (Forthcoming).

Hausman, Jerry . 1978. "Specification Tests in Econometrics." Econometrica 46: 1251-71.

Hodrick, Robert. 1987. The Empirical Evidence on the Efficiency of Forward and Future Foreign Exchange Markets. (Harwood; Forthcoming.)

Hodrick, Robert and Sanjay Srivastava. 1984. "An Investigation of Rdsk and Return in Forward Foreign Exchange." Journal of Internatinal Money and Finance 3: 5-29.

- 1986. "The Covariation of Risk Premiums and Expected Future Spot Exchange Rates ." Journal of International Money and Finance. (Supplement): S5-22.

Hooper, Peter. 1985. "International Repercussions of the U.S. Budget Deficit." Brookings Discussion Papers, No. 27 (February).

Hooper, Peter and John Morton. 1982. "Fluctuations in the Dollar: A Model of Nominal and Real Exchange Rate Determination." Journal of International Money and Finance 1: 39-56.

Hsieh, David. 1984. "Tests of Rational Expectations and No Risk Premium in Forward Exchange Markets." Journal of International Economics 17: 173-84.

Hsieh, David and Luis Manas-Anton. 1986. "Empirical Regularities in the Deutsch Mark Futures Options." Center for Research in Security Prices, Working Paper No. 189. University of Chicago.

Huang, Roger. 1984. "Some Alternative Tests of Forward Exchange Rates as Predictors of Future Spot Rates." Journal of International Money and Finance 3, 2 (August): 153-67.

Huizinga, John. 1986. "An Empirical Investigation of the Long Run Behavior of Real Exchange Rates." University of Chicago mimeo. 
- 1979. "Empirical Regularities in the Behavior of Exchange Rates and Theories of the Foreign Exchange Market." Carnegie-Rochester Series on Public Policy, No. 11: 9-57.

Obstfeld, Maurice. 1986. "How Integrated are World Capital Markets? Some New Tests." NBER Working Paper, No. 2075.

Pagan, Adrian. 1986. "A Note on the Magnitude of Risk Premia." University of Rochester mimeo:

Phillips, P. C. B. 1985. "THme Series Regression with Unit Root." Cowles Foundation Discussion Paper, No. 740 .

Pigott, Charles and Richard Sweeney. 1985. In Exchange Rates, Trade and the U.S. Economy, edited by S. Arndt, R. Sweeney and T. Willett. (Washington, D.C.: American Enterprise Institute).

Pippenger, John. 1986. "Arbitrage and Efficient Markets Interpretations of Purchasing Power Parity: Theory and Evidence." Federal Reserve Bank of San Francisco Review (Forthcoming, Winter).

Poole, William. 1967. "Speculative Prices as Random Walks: An Analysis of Ten THme Series of Flexible Exchange Rates ." Southern Economic Journal 33: 468-78.

Poterba, James and Lawrence Summers. 1986. "The Persistence of Volatility and Stock Market Fluctuations." American Economic Review 76,5 (December): 1142-51.

Richard, Scott and M. Sundaresan. 1981. "A Continuous Tlme Equilibrium Model of Forward Prices and Future Prices in a Multigood Economy ." Journal of Financial Economics 9: 347-72.

Rodriguez, Carlos. 1980. "The Role of Trade Flows in Exchange Rate Determination: A Rational Expectations Approach." Journal of Political Economy 88: 1148-58.

Rogoff, Kenneth. 1979. "Essays on Expectations and Exchange Rate Volatility." Unpublished Ph .D. dissertation, M.I.T.

- 1984. "On the Effects of Sterilized Intervention: An Analysis of Weekly Data." Journal of Monetary Economics 14: $133-50$.

Roll, Richard. 1979. "Violations of Purchasing Power Parity and Their Implications for Efficient International Commodity Markets ." In International Trade and Finance, Vol. 1, edited by M. Sarnat and G. Szego. (Cambridge: Ballinger).

Sachs, Jeffrey. 1985. "The Dollar and the Pollcy Mix: 1985." Brookings Papers on Economic Activity 1: 117-85. 
Mckibbon, Warwick and Jeffrey Sachs. 1986. "Comparing the Global Performance of Alternative Exchange Arrangements ." NBER Working Paper, No. 2024 (September).

McKinnon, Ronald. 1976. "Floating Exchange Rates 1973-74: The Emperor's New Clothes." Carnegie-Rochester Conference Series on Public Pollicy, No. 3: 79-114.

Marsh, T. and R. Merton. 1986. "Dividend Variability and Variance Bounds Tests for the Rationality of Stock Market Prices." American Economic Review.

Mattey, Joe and Richard Meese. 1987. "Empirical Assessment of Present Value Relations." Econometric Reviews (Forthcoming).

Meese, Richard. 1986. "Testing for Bubbles in Exchange Rates: A Case of Sparkling Rates?" Journal of Political Economy: 345-73.

Meese, RIchard. 1987. "Emplrical Assessment of Foreign Ourrency RIsk Premiuns." Federal Reserve Bank of St. Louis Academic Conference, November 1986 (Forthcoming).

Meese, Richard and Kenneth Rogoff. 1983a. "Empirical Exchange Rate Models of the Seventies: Do They Flt Out of Sample?" Journal of International Economics 14 (February): 3-24.

- 1983b. "The Out-of-sample Failure of Empirical Exchange Rate Models: Sampling Error or Misspecification?" In Exchange Rates and International Macroeconomics, edited by $\mathrm{J}$. Frenkel. (Chicago: University of Chicago Press).

- 1986. "Was it Real? The Exchange Rate-Interest Differential Relation, 1973-1984." NBER Working Paper.

Meese, Richard and Kenneth Singleton. 1982. "On Unit Roots and the Empirical Modeling of Exchange Rates." Journal of Finance (September): 1029-35.

- 1983. "Rational Expectations and the Volatility of Floating Exchange Rates." International Ecoomic Review: 721-33.

Mishkin, Frederic. 1984. "Are Real Interest Rates Equal Across Countries? An Empirical Investigation of International Parity Conditions." Journal of Finance 39: 1345-58.

Mussa, Michael. 1976. "The Exchange Rate, The Balance of Payments, and Monetary and Fiscal Policy Under a Regime of Controlled Floating." Scandinavian Journal of Economics 78: 229-48. 